\title{
Sensitivity of a Greenland ice sheet model to atmospheric forcing fields
}

\author{
A. Quiquet ${ }^{1}$, H. J. Punge ${ }^{2, *}$, C. Ritz ${ }^{1}$, X. Fettweis ${ }^{3}$, H. Gallée ${ }^{1}$, M. Kageyama ${ }^{2}$, G. Krinner ${ }^{1}$, D. Salas y Mélia ${ }^{4}$, and \\ J. Sjolte ${ }^{5, * *}$ \\ ${ }^{1}$ UJF - Grenoble 1/CNRS, Laboratoire de Glaciologie et Géophysique de l'Environnement (LGGE) UMR 5183, \\ Grenoble, 38041, France \\ ${ }^{2}$ Laboratoire des Sciences du Climat et de l'Environnement (LSCE)/IPSL, CEA-CNRS-UVSQ, UMR 8212, \\ 91191 Gif-sur-Yvette, France \\ ${ }^{3}$ Département de Géographie, Université de Liège, Liège, Belgium \\ ${ }^{4}$ CNRM-GAME, URA CNRS-Météo-France 1357, Toulouse, France \\ ${ }^{5}$ Center for Ice and Climate, Niels Bohr Institute, Copenhagen, Denmark \\ * now at: Institute for Meteorology and Climate Research, Karlsruhe Institute of Technology, Karlsruhe, Germany \\ ** now at: GeoBiosphere Science Centre, Quaternary Sciences, Lund University, Sölvegatan 12, 22362 Lund, Sweden
}

Correspondence to: A. Quiquet (aurelien.quiquet@1gge.obs.ujf-grenoble.fr)

Received: 13 February 2012 - Published in The Cryosphere Discuss.: 15 March 2012

Revised: 19 July 2012 - Accepted: 1 August 2012 - Published: 18 September 2012

\begin{abstract}
Predicting the climate for the future and how it will impact ice sheet evolution requires coupling ice sheet models with climate models. However, before we attempt to develop a realistic coupled setup, we propose, in this study, to first analyse the impact of a model simulated climate on an ice sheet. We undertake this exercise for a set of regional and global climate models. Modelled near surface air temperature and precipitation are provided as upper boundary conditions to the GRISLI (GRenoble Ice Shelf and Land Ice model) hybrid ice sheet model (ISM) in its Greenland configuration.

After 20 kyrs of simulation, the resulting ice sheets highlight the differences between the climate models. While modelled ice sheet sizes are generally comparable to the observed one, there are considerable deviations among the ice sheets on regional scales. These deviations can be explained by biases in temperature and precipitation near the coast. This is especially true in the case of global models. But the deviations between the climate models are also due to the differences in the atmospheric general circulation. To account for these differences in the context of coupling ice sheet models with climate models, we conclude that appropriate downscaling methods will be needed. In some cases, systematic corrections of the climatic variables at the interface may be required to obtain realistic results for the Greenland ice sheet (GIS).
\end{abstract}

\section{Introduction}

Recent growing awareness of the possible consequences of global warming on ice sheets (4th assessment report of the Intergovernmental Panel on climate change, IPCC-AR4, Meehl et al., 2007) has led to the developing of numerical models aiming to predict their future evolution. While estimates of surface mass balance (SMB) from climate models give insights into the response of the ice sheet surface to climate warming (e.g., Yoshimori and Abe-Ouchi, 2012), ice sheet models (ISMs) must also be used to simulate the longterm evolution of ice sheets (e.g., Robinson et al., 2010). At the same time, awareness of the importance of feedback from other components of the Earth system has risen and several attempts have been undertaken to integrate ISMs into climate models in order to include and evaluate these feedback mechanisms for the upcoming centuries (Ridley et al., 2005; Vizcaíno et al., 2008, 2010). These feedbacks include, for example, water fluxes to the ocean (Swingedouw et al., 2008), orography variations (Kageyama and Valdes, 2000) and albedo changes (Kageyama et al., 2004).

However, when model results are compared with actual observations, major uncertainties remain due to shortcomings in both climate models and ISMs. Because of the long time scales involved in ice sheet development, synchronous 
coupling is feasible only with low resolution and physically simplified earth system models (e.g., Fyke et al., 2011; Driesschaert et al., 2007). Direct synchronous coupling with a fine resolution using a physically sophisticated atmospheric general circulation model (GCM) is still a challenge (Pollard, 2010). Recent approaches try to avoid this problem by implementing asynchronous coupling of the climate models and ISMs (Ridley et al., 2010; Helsen et al., 2012).

The recent observations of fast processes at work in the Greenland and West Antarctic ice sheets (e.g., Joughin et al., 2010) show the need for synchronous coupling between the ISMs that represent these processes and coupled atmosphereocean GCMs (AOGCMs) if we want to predict the state of the ice sheets in the near future, i.e., the coming century. The ISMs should include fast processes such as fast flowing ice streams and grounding line migration. These ISMs are becoming available (Ritz et al., 2001; Bueler and Brown, 2009) and the first step towards their coupling to GCMs is to examine how they perform when forced by the GCM outputs. Until recently, the major concern of ISM developers was to improve the representation of physical processes occurring inside or at the boundaries of the ice sheet (e.g., Ritz et al., 1997; Tarasov and Peltier, 2002; Stone et al., 2010), primarily in order to better simulate past ice sheet evolution. In reconstructions of the paleo-climate, ISMs are often forced by ice core-derived proxy records, with spatial resolution of atmospheric conditions stemming from reanalysis (e.g., Bintanja et al., 2002), or from climate model snapshots (Letréguilly et al., 1991; Greve, 1997; Tarasov and Peltier, 2002; Charbit et al., 2007; Graversen et al., 2010). But for reliable projections of the future ice sheet state the explicit use of climate model scenarios is necessary. More specifically, the first test is to evaluate how a Greenland ISM responds when forced by output from different GCMs. Considering that the extent of the ablation zone is often less than $100 \mathrm{~km}$ (van den Broeke et al., 2008), the GCMs generally have a coarse resolution compared with the typical ISMs. We consequently need to assess the gain provided by higher resolution models, such as regional climate models (RCMs), even if the trade off is a more limited scope.

To date, few studies have tested the sensitivity of an ISM to atmospheric forcing fields explicitly. Charbit et al. (2007) showed that an ISM forced by six GCMs simulations from the Paleo Climate Intercomparison Project (PMIP) was unable to reproduce the last deglaciation of the Northern Hemisphere. They showed great discrepancies between the six simulated ice volume evolutions. The fast processes mentioned earlier were not included in this study because the ISM they used does not include ice streams representation. Graversen et al. (2010) simulated the total sea level increase over the next century using the GCMs from the Coupled Model Intercomparison Project phase 3 (CMIP-3). Here again, the ISM they used does not take into account the ice streams. Although different climate model outputs were used as forcing fields, neither the studies mentioned above, nor the parameter-based approaches (e.g., Hebeler et al., 2008; Stone et al., 2010), illustrate directly the links between climate forcing and simulated ice sheet behaviour. That is the main goal of the present study.

We present and discuss some of the difficulties arising when combining ice sheet and climate models. We restrict our study to the case of Greenland and choose an uncoupled approach: to examine the sensitivity of a single state-of-theart Greenland ice sheet (GIS) model to atmospheric input fields stemming from a number of selected climate models. Then, for comparison and in the tradition of previous ISM studies, we examine a reference case derived from meteorological observations.

In Sect. 2, we first present our state-of-the-art ISM and its specifications. We then explain how we selected the climate models with different degrees of resolution and comprehensiveness. The downscaling of atmospheric variables and the SMB computation is then described. Finally, we discuss how we calibrated the ISM and set it up for the sensitivity experiments. The results of the ISM simulations are shown in Sect. 3. The links between the climate model biases and horizontal resolution on the one hand, and simulated deviations in ice sheet size and shape on the other hand are discussed. Our conclusions and suggestions for future directions to explore in climate-ice sheet model studies are presented in Sect. 4.

\section{Tools and methodology}

\subsection{The GRISLI ice sheet model}

The model used here is a three-dimensional thermomechanically coupled ISM called GRISLI. With respect to ice flow dynamics, it belongs to the hybrid model type: it includes both the shallow ice approximation (SIA, Hutter, 1983) and the shallow shelf approximation (SSA, MacAyeal, 1989) to solve the Navier-Stokes equations. This model has been validated on the Antarctic ice sheet (Ritz et al., 2001; Philippon et al., 2006; Álvarez-Solas et al., 2011a) and has been successfully applied on the northern hemisphere ice sheets for paleo-climate experiments (Peyaud et al., 2007; Álvarez-Solas et al., 2011b). In the more recent version used here, the combination of SIA and SSA is the following:

1. A map of "allowed" ice streams is determined on the basis of basal topography. More specifically, we assume that ice streams are located in the bedrock valleys (Stokes and Clark, 1999). These valleys are derived from the difference between bedrock elevation at any given grid point and bedrock elevation smoothed over a $200-\mathrm{km}$ radius around this point. Additionally, ice streams are allowed where observed present-day velocities (Joughin et al., 2010) are greater than $100 \mathrm{~m} \mathrm{yr}^{-1}$ even if the bedrock criterion is not fulfilled. 
2. Ice streams are activated only if the temperature at the ice-bedrock interface reaches the melting point. In this case, the SSA is used as a sliding law (Bueler and Brown, 2009). As in MacAyeal (1989), basal drag is assumed to be proportional to basal velocity; this relationship corresponds to a linear viscous sediment type. In the experiments presented here, the proportionality coefficient, $\beta$, assumed to be the same for all ice streams, is one of the parameters of the model that will be calibrated by comparison with observed velocities (see Sect. 2.4.1).

3. Where ice streams are not allowed or not activated, the grounded ice flow is computed using the SIA only. Ice shelves are processed with SSA only.

Calving is parameterised with a simple cut-off based on a threshold on the ice thickness. This threshold is spatially uniform but time-dependent. Its value varies with the surface temperature anomaly used in the spin-up experiment presented in Sect. 2.4.1. For the present climate, the threshold is $250 \mathrm{~m}$.

One of the features of the GRISLI model is a polynomial constitutive equation, that combines the strain rate components from Glen and Newtonian flow laws. This kind of law, already used in Ritz et al. (1983), accounts for the fact that the exponent of the flow law depends on the stress range (Lliboutry and Duval, 1985). Additionally, as in most large scale ISMs, we use enhancement factors that are multiplication coefficients supposed to represent the impact of ice anisotropy on deformation. According to Ma et al. (2010), enhancement factors are different for SIA and SSA because the impact on the rate of deformation of the fabric, typically with a vertically oriented C-axis, depends on the stress regime. We, thus, have four different enhancement factors, one for each component of the flow law (Newtonian or Glen) and for SIA and SSA (here called $E_{1}^{\text {SIA }}$ and $E_{3}^{\text {SIA }}$ for SIA Newtonian and Glen, respectively, and $E_{1}^{\text {SSA }}$ and $E_{3}^{\text {SSA }}$ for SSA Newtonian and Glen, respectively). These factors are not completely independent because the stronger a factor is for SIA, the smaller it is for SSA. These four enhancement factors are tuned during the dynamic calibration procedure (see Sect. 2.4.1 below and Table 1 for the values).

The model is run on a $15-\mathrm{km}$ Cartesian grid resulting from the stereographic projection with the standard parallel at $71^{\circ} \mathrm{N}$ and the central meridian at $39^{\circ} \mathrm{W}$. The bedrock elevation map comes from the ETOPO1 dataset, which itself combines other maps (Amante and Eakins, 2009). The ice sheet thickness map is derived from the work of Bamber et al. (2001). The surface elevation is the sum of the bedrock elevation and ice thickness. Figure 1 presents the initial topography, which is also referred to as the observed topography. Note that under this construction there are no floating points at the time of initialisation. We use the geothermal heat flux distribution proposed by Shapiro and Ritzwoller (2004).

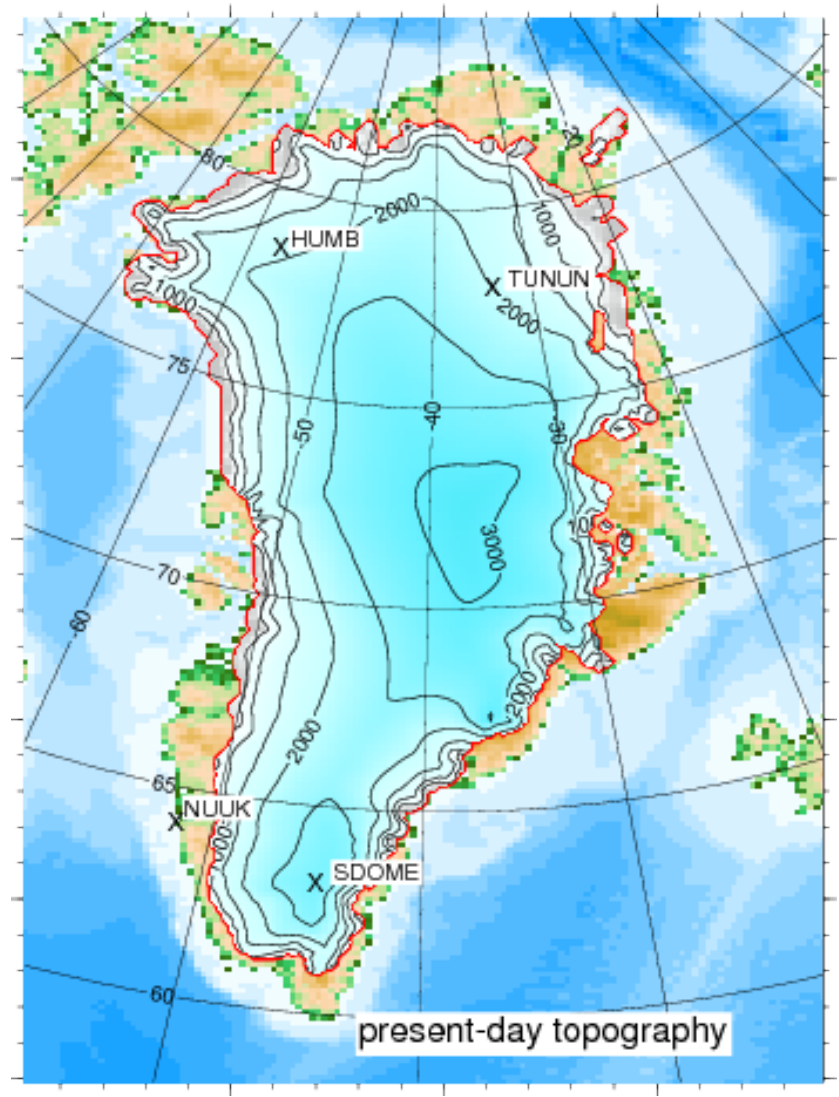

Fig. 1. Present day topography of the GIS, used to initialise the ISM. Selected weather stations are represented.

The procedure to initialise the thermal state of the ice sheet is described in Sect. 2.4.

\subsection{Atmospheric model forcing fields}

The ISM requires the climatological monthly mean values for the near surface air temperature and precipitation as well as the surface topography for the corresponding atmospheric forcings. These are derived from a common 20-year reference period, 1980-1999. The length of 20 years is a compromise between the need for meaningful climatology on the one hand and the consistency of boundary conditions used for driving the regional models and reanalysis on the other hand.

Among the CMIP-3 coupled atmosphere-ocean GCMs used for the IPCC-AR4, there are significant discrepancies regarding the Greenland climate (Franco et al., 2011; Yoshimori and Abe-Ouchi, 2012). We selected two models with reasonable agreement to reanalysis (Franco et al., 2011), but diverging mass balance projections, as discussed in Yoshimori and Abe-Ouchi (2012):

- The coupled atmosphere-ocean GCM CNRM-CM3 (Salas-Mélia et al., 2005). 
Table 1. Model parameters used in the GRISLI model for this study.

\begin{tabular}{lll}
\hline Variable & Identifier name & Value \\
\hline Basal drag coefficient & $\beta$ & $1500 \mathrm{~m} \mathrm{yr} \mathrm{Pa}^{-1}$ \\
SIA enhancement factor, Glen & $E_{3}^{\text {SIA }}$ & 3 \\
SIA enhancement factor, linear & $E_{1}^{\text {SIA }}$ & 1 \\
SSA enhancement factor, Glen & $E_{3}^{\text {SSA }}$ & 0.8 \\
SSA enhancement factor, linear & $E_{1}^{\text {SSA }}$ & 1 \\
Transition temperature of deformation, Glen & $T_{3}^{\text {trans }}$ & $-6.5^{\circ} \mathrm{C}$ \\
Activation energy below transition, Glen & $Q_{3}^{\text {cold }}$ & $7.820 \times 10^{4} \mathrm{~J} \mathrm{~mol}^{-1}$ \\
Activation energy above transition, Glen & $Q_{3}^{\text {warm }}$ & $9.545 \times 10^{4} \mathrm{~J} \mathrm{~mol}^{-1}$ \\
Transition temperature of deformation, linear & $T_{1}^{\text {trans }}$ & $-10{ }^{\circ} \mathrm{C}$ \\
Activation energy below transition, linear & $Q_{1}^{\text {cold }}$ & $4.0 \times 10^{4} \mathrm{~J} \mathrm{~mol}^{-1}$ \\
Activation energy above transition, linear & $Q_{1}^{\text {warm }}$ & $6.0 \times 10^{4} \mathrm{~J} \mathrm{~mol}^{-1}$ \\
\hline Topographic lapse rate, July & $l_{\text {July }}$ & $5.426^{\circ} \mathrm{Ckm}^{-1}$ \\
Topographic lapse rate, annual & $\operatorname{lr}_{\text {ann }}$ & $6.309^{\circ} \mathrm{Ckm}^{-1}$ \\
Precipitation ratio parameter & $\gamma$ & $0.07^{\circ} \mathrm{C}^{-1}$ \\
PDD standard deviation of daily temperature & $\sigma$ & $5.0{ }^{\circ} \mathrm{C}$ \\
PDD ice ablation coefficient & $C_{\text {ice }}$ & $8.0 \mathrm{~mm} \mathrm{day}^{-1 \circ} \mathrm{C}^{-1}$ \\
PDD snow ablation coefficient & $C_{\text {snow }}$ & $5.0 \mathrm{~mm} \mathrm{day}^{-1} \mathrm{C}^{-1}$ \\
\hline
\end{tabular}

- The coupled atmosphere-ocean GCM IPSL-CM4 (Marti et al., 2010).

Surface climate fields were extracted from the CMIP-3 20th century transient simulations for years 1980 to 1999 .

In addition, as an example of an atmosphere-only model with GCM resolution, we included the atmospheric component of the IPSL model, but in a version with an improved physical ice sheet surface scheme, as follows:

- The global atmosphere-only GCM, LMDZ, with an explicit snow model adapted from the SISVAT model, as used in the regional model MAR (Brun et al., 1992; Gallée et al., 2001), termed LMDZSV. Here and for the following climate models, we imposed SST and sea ice boundary conditions for the years 1980-1999. The introduction of a more realistic snow scheme on ice sheets makes this version of LMDZ very different from the standard one in terms of surface climate (Punge et al., 2011).

This climate forcing is meant to identify the impact of an improved representation of surface climate processes in a GCM on ice sheet evolution.

To study the impact of resolution in a GCM, we also considered:

- The global atmosphere-only GCM LMDZ4 with an improved resolution on Greenland (Krinner and Genthon, 1998; Hourdin et al., 2006), termed LMDZZ (for zoom).

The much higher resolution over Greenland compared with IPSL-CM4 induces scaling effects of the parameterisations which leads to very different surface climates. In particular, the impact of orography near the coast is much better represented in the zoomed model, and it can influence moisture transport and temperature over the entire ice sheet.

Regional climate models achieve much higher spatial resolution than GCMs, but require lateral boundary conditions. We selected:

- The regional climate model MAR (Fettweis, 2007; Lefebre et al., 2002). The model output we used stems from the 1958-2009 simulation (Fettweis et al., 2011), forced by ERA40 as boundary conditions. We use the near surface air temperatures at $3 \mathrm{~m}$ provided by the MAR output, instead of $2 \mathrm{~m}$ temperatures used in all other cases, but this is not likely to affect our analysis significantly.

- The regional climate model REMO (Sturm et al., 2005; Jacob and Podzun, 1997), as used in a recent isotope study on Greenland precipitation (Sjolte et al., 2011), forced by ECHAM4 as lateral boundary conditions and nudged to the upper level wind field. The ECHAM4 simulation is itself nudged towards the ERA40 wind and temperature fields every six hours. For a complete description of the nudging procedure, see von Storch et al. (2000).

As for the GCMs, this selection is in no way meant to be complete. It was guided in part by the availability of the model output at the beginning of the study, but still represents the state-of-the-art climate representation. 


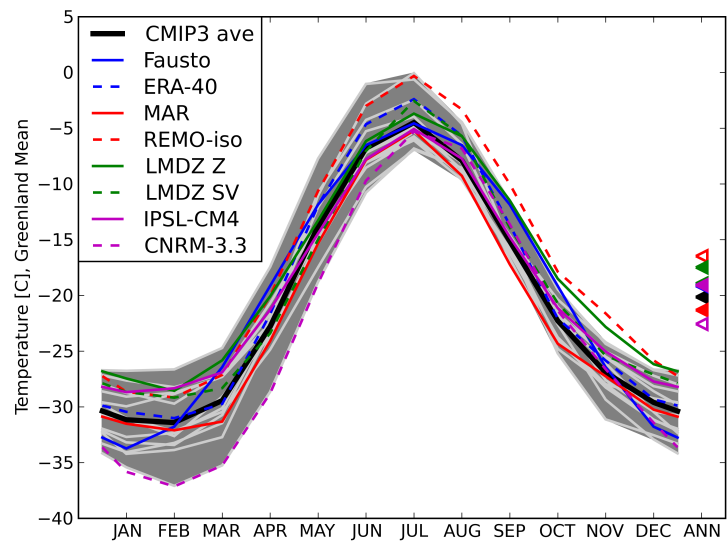

(a)

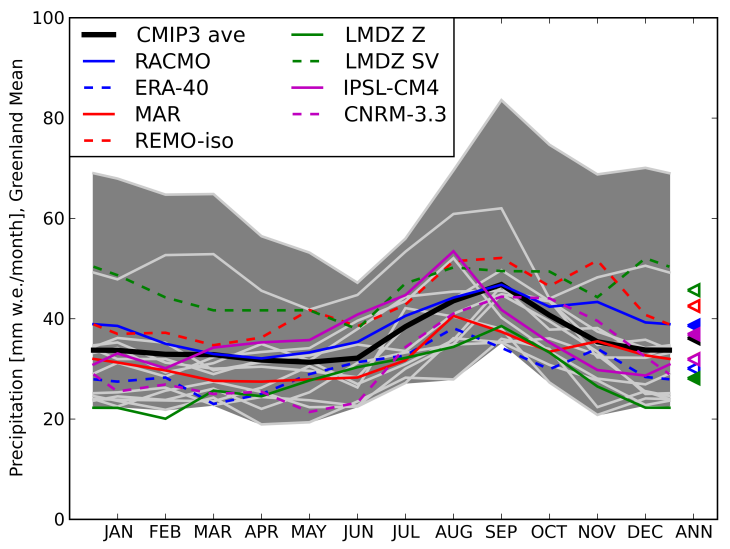

(b)

Fig. 2. Greenland (land points) mean seasonal cycle of near surface air temperature (in ${ }^{\circ} \mathrm{C}$, left panel) and precipitation (in millimetres of water equivalent per month, right panel) for the 8 atmospheric forcing fields used in this study (coloured lines). For FE09, temperature is representative for the 1996-2006 period (Fausto et al., 2009) and precipitation for the 1958-2009 period (Ettema et al., 2009). For the other forcing fields, climatological means are evaluated on the 1980-1999 period. Annual mean values are represented by triangles on the right. The grey, shaded area is the spread of 12 CMIP-3 models. Light grey and black lines, respectively, represent individual models and their means.

As an example for a reanalysis, we further used:

- The reanalysis ERA40 (Uppala et al., 2005).

Finally, in our comparison we include a composite atmospheric field using parameterised temperature based on geographical coordinates and altitudes together with highresolution assimilation-based precipitation fields, as frequently used by ice sheet modellers (e.g., Ritz et al., 1997; Greve, 2005). It consists of:

- The temperature parameterisation of Fausto et al. (2009) and the precipitation field of the regional model RACMO2 (Ettema et al., 2009) run with ERA40 as boundary conditions over the 1958-2009 time span. We will refer to this forcing set as FE09. The FE09 atmospheric forcing field was distributed by the CISM community and used, for example, in Greve et al. (2011).

From the ice sheet modellers point of view, this forcing field may be regarded as a reference.

The different model resolutions and external forcings are summarised in Table 2.

The AOGCMs simulate atmospheric surface conditions in interaction with their ocean and sea ice components and with none or few external sources of variability. Hence, the simulated time series cannot be expected to correlate with observed variables as in the atmosphere-only models with observation-derived lower boundary conditions.

In terms of annual mean near surface air temperature and precipitation, the atmospheric forcing fields used in this study are within the range of the CMIP-3 models, but reflect the broad dispersion, as shown in Fig. 2. We chose to use temperature and precipitation forcing fields from various models. These forcing fields are outputs from coupled atmosphere-ocean GCMs, atmosphere-only GCMs, regional models and reanalysis. We assume that the range of uncertainty of CMIP-3 models is a conservative estimate of the uncertainty of observed temperature and precipitation in Greenland. Figure $2 \mathrm{a}$ shows that the temperature spread among the model outputs we selected is comparable to that of the CMIP3 models. By contrast, the precipitation spread among the forcing fields we selected is smaller than that of the CMIP3 models (Fig. 2b). Note, however, that the spread of the CMIP-3 ensemble is artificially increased by one model that probably overestimates the total amount of precipitation over Greenland.

Figures 3 and 4 show the 1980-1999 climatological annual mean $2 \mathrm{~m}$ temperature and precipitation, respectively, on and around Greenland. On these figures, the original polar stereographic grid was preserved for MAR and FE09; the results of the other models are presented on polar stereographic projections. Several large scale features can be seen in Fig. 3: the MAR and CNRM models have relatively low temperatures in central and northern Greenland, while REMO is warmer than the other models on the ice sheet, and CNRM seems to be too warm on the southern part of the GIS. Even if the coarse resolution global models fail to resolve the fine pattern of the coastal high precipitation zone (Fig. 4), all the climate models simulate correctly a precipitation maximum in SouthEast Greenland. However, the amplitude of this maximum is too low for MAR and ERA40. CNRM is the driest model in the northern part of the GIS. Section 3 will show how these different climatic conditions, caused by different representations of orography and boundary conditions, but also by different dynamical schemes and physical parameterisations, affect the simulated ice sheet. 
Table 2. Main characteristics of atmospheric forcing fields used for this study.

\begin{tabular}{|c|c|c|c|c|}
\hline Dataset & $\begin{array}{l}\text { Atmosphere } \\
\text { resolution }\end{array}$ & $\begin{array}{l}\text { Lateral } \\
\text { bounds }\end{array}$ & $\begin{array}{l}\text { Ocean bound. } \\
\text { conditions }\end{array}$ & Reference \\
\hline $\begin{array}{l}\text { Fausto/Ettema } \\
\text { FE09 }\end{array}$ & $\begin{array}{l}\text { Fausto }(\mathrm{t} 2 \mathrm{~m}) \\
\text { RACMO } 2 / \mathrm{GR} \text { (precip.), } \\
0.29^{\circ} \times 0.29^{\circ}, \mathrm{L} 40^{*}\end{array}$ & ERA40* & $\begin{array}{l}\text { obs. derived } \\
\text { ERA40* }\end{array}$ & $\begin{array}{l}\text { Fausto et al. (2009) } \\
\text { Ettema et al. (2009) }\end{array}$ \\
\hline ERA-40 & $\begin{array}{l}\text { ERA40, } \\
1.125^{\circ} \times 1.125^{\circ}, \mathrm{T} 159 \mathrm{~L} 60\end{array}$ & - & $\begin{array}{l}\text { obs. derived } \\
\text { HadISST/NCEP }\end{array}$ & Uppala et al. (2005) \\
\hline MAR & $\begin{array}{l}\text { MAR, } \\
0.66^{\circ} \times 0.66^{\circ}\end{array}$ & ERA40 & $\begin{array}{l}\text { obs. derived } \\
\text { ERA40 }\end{array}$ & Fettweis (2007) \\
\hline REMO & $\begin{array}{l}\text { REMO, } \\
0.5^{\circ} \times 0.5^{\circ}, \mathrm{L} 19\end{array}$ & ECHAM4 & $\begin{array}{l}\text { obs. derived } \\
\text { ERA40 }\end{array}$ & Sturm et al. (2005) \\
\hline LMDZ-zoom & $\begin{array}{l}\text { LMDZ4, } \\
1.2-3.6^{\circ} \times 0.5-5.5^{\circ}, \mathrm{L} 19\end{array}$ & - & $\begin{array}{l}\text { obs. derived } \\
\text { AMIP2 }\end{array}$ & Krinner and Genthon (1998) \\
\hline LMDZ-SISVAT & $\begin{array}{l}\text { LMDZ4, } \\
3.75^{\circ} \times 2.5^{\circ}, \mathrm{L} 19\end{array}$ & - & $\begin{array}{l}\text { obs. derived } \\
\text { AMIP2 }\end{array}$ & Punge et al. (2011) \\
\hline IPSL-CM4 & $\begin{array}{l}\text { LMDZ4, } \\
3.75^{\circ} \times 2.5^{\circ}, \mathrm{L} 19\end{array}$ & - & $\begin{array}{l}\text { coupled } \\
\text { ORCA model }\end{array}$ & Marti et al. (2010) \\
\hline CNRM-CM3.3 & $\begin{array}{l}\text { ARPEGE-Climat } 3 \\
1,9^{\circ} \times 1.9^{\circ}, \text { T63 L45 }\end{array}$ & - & $\begin{array}{l}\text { coupled } \\
\text { OPA } 8 \text { model }\end{array}$ & Salas-Mélia et al. (2005) \\
\hline
\end{tabular}

Resolutions in ${ }^{\circ}$ approximated. *: for RACMO2/GR

\subsection{SMB computation}

The ISM is forced by the atmospheric fields described in Sect. 2.2. To compute the SMB, we use monthly means of temperature and precipitation for present day climate. Even if the SMB is an output of the atmospheric models, we cannot use it directly for the ISM because of the large difference in resolution between the two grids. Innovative techniques using SMB gradients exist (Helsen et al., 2012), but are strictly limited to high resolution climate models with sophisticated snow schemes and consequently exclude GCMs. The downscaling of near surface air temperature and precipitation is physically based, as detailed below, contrary to the SMB downscaling, which is not. Thus, we compute the SMB from downscaled temperature and precipitation means.

Ablation is computed with the widely-used Positive Degree Days (PDD) method (Reeh, 1991). Even if this method is a very schematic representation of surface melt (van den Broeke et al., 2010), it can be tuned to simulate the observed SMB and its variability (Tarasov and Peltier, 2002; Fausto et al., 2009b), consequently it is still commonly used among the glaciologist community (e.g., Peyaud et al., 2007; Greve et al., 2011; Kirchner et al., 2011; Graversen et al., 2010). We also chose this method because it requires a limited number of atmospheric fields, which are easy to obtain from the different models. We compute the number of PDD, representing melt capacity, numerically at each grid point, based on the downscaled monthly mean near-surface temperature. Following Reeh (1991), a statistical temperature variation is considered, allowing melt even in months with mean temper- ature below the freezing point. The melt capacity computed with the PDD method is first used to melt the snow layer. A fraction of the melted snow is allowed to percolate into the snowcover and refreeze, generating superimposed ice. Melt water runoff is allowed if the amount of superimposed ice reaches the limit of $60 \%$ of the snowcover (Reeh, 1991). The refreezing is responsible for firn warming, as described in Reeh (1991). The remaining PDD are used to melt possible superimposed ice from refreezing and then old ice.

The PDD integration constants and the melt rates of snow and ice are listed in Table 1 . We chose $C_{\text {snow }}$ to be substantially higher than in Reeh (1991). But the melting rate coefficients are poorly constrained and a wide range of values can be found in the literature (van den Broeke et al., 2010). This choice was motivated by the better agreement of ablation with the one simulated in regional models (Fettweis et al., 2011; Ettema et al., 2009).

The ISM distinguishes between rainfall and snowfall. Liquid precipitation does not contribute to the surface mass balance and is assumed to run off instantaneously. This procedure is a drastic simplification, but still commonly employed (Charbit et al., 2007; Peyaud et al., 2007; Hubbard et al., 2009; Kirchner et al., 2011). An explicit refreezing model (Janssens and Huybrechts, 2000) was tested, but produced only slight differences (not shown). The monthly solid precipitation, $P_{\mathrm{sm}}$, is calculated based on total monthly precipitation $P_{\mathrm{m}}$ and monthly near surface air temperature $T_{\mathrm{m}}$, following Marsiat (1994): 

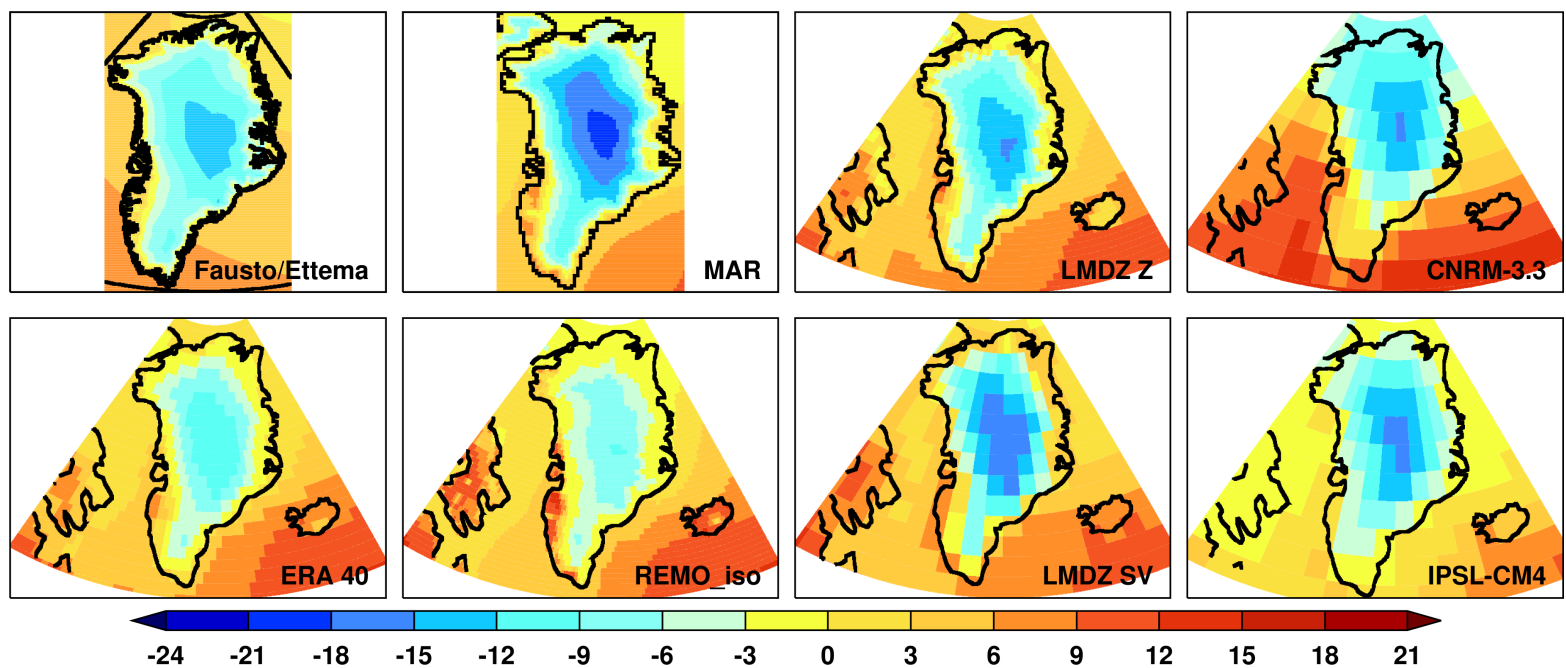

Fig. 3. Climatological (1980-1999) June-July-August mean $2 \mathrm{~m}$ temperature in the eight different climate models (in ${ }^{\circ} \mathrm{C}$ ).
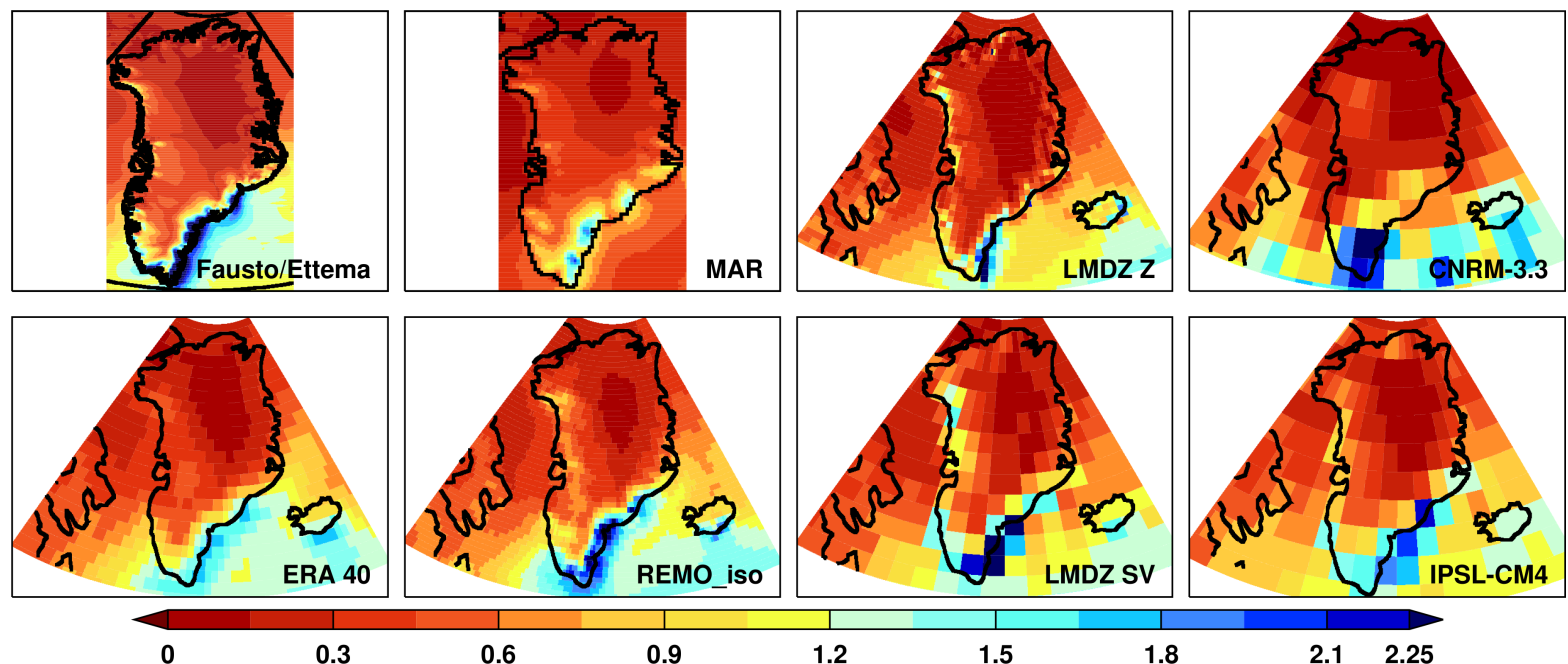

Fig. 4. Climatological (1980-1999) annual mean precipitation (solid + liquid) in the eight different climate models (in metres of ice equivalent).

$$
\frac{P_{\mathrm{sm}}}{P_{\mathrm{m}}}= \begin{cases}0, & T_{\mathrm{m}} \geq 7^{\circ} \mathrm{C} \\ \left(7^{\circ} \mathrm{C}-T_{\mathrm{m}}\right) / 17^{\circ} \mathrm{C}, & -10^{\circ} \mathrm{C} \geq T_{\mathrm{m}} \geq 7^{\circ} \mathrm{C} \\ 1, & T_{\mathrm{m}} \leq-10^{\circ} \mathrm{C}\end{cases}
$$

As the ice sheet topography changes during the simulation, and can hence differ strongly from the one prescribed in the atmospheric models, the near surface air temperature has to be adapted. For this correction, we use a vertical temperature gradient, referred to hereafter as topographic lapse rate, which does not vary spatially, but is different from month to month. The monthly values follow an annual sinusoidal cycle with a minimum in July at $5.426{ }^{\circ} \mathrm{C} \mathrm{km}^{-1}$ and an annual mean of $6.309^{\circ} \mathrm{C} \mathrm{km}^{-1}$. They are derived from the
Greenland surface temperature parameterisation proposed by Fausto et al. (2009). The adaptation method is, thus, consistent with the FE09 reference experiment. The gradients obtained in this way are derived from spatial variations of near surface air temperature and not from the actual temperature response to surface elevation changes at each grid point. This information could be obtained only by repeated atmospheric model simulations with different topographies, as performed by Krinner and Genthon (1999), who found values that are close to the ones we use here. The hypothesis that the sensitivity of the results to topographic lapse rate is of secondary order compared to the different forcing fields is tested in Sect. 3.5. 
The temperature field from the low resolution topography of the climate model $\left(T_{0}\right)$ is downscaled to the high resolution required for the ISM ( $\left.T_{\text {ref }}\right)$ using the topographic lapse rate correction as described above. For the downscaling of the precipitation rate, we used an empirical law that links temperature differences to accumulation ratio (Ritz et al., 1997):

$$
\frac{P_{\text {ref }}}{P_{0}}=\exp \left(-\gamma \times\left(T_{\text {ref }}-T_{0}\right)\right)
$$

in which the ratio of precipitation change with temperature change, $\gamma$, is poorly constrained (Charbit et al., 2002). We use a value of $\gamma=0.07$, which corresponds to a $7.3 \%$ change of precipitation for every $1{ }^{\circ} \mathrm{C}$ of temperature change (Huybrechts, 2002).

We chose to use the same parameters for SMB calculations for all atmospheric forcings, because our goal is to compare the sensitivity of the ISM to the forcing, not to determine the parameters which yield the most realistic GIS for each forcing.

\subsection{Experimental setup of the ice sheet model}

\subsubsection{Spin-up and dynamic calibration}

The calibration/initialisation of an ISM is a difficult problem that would require assimilation methods to be accurately solved (Arthern and Gudmundsson, 2010). In the experiments presented here we wanted to start from fields as close as possible to the present state. The prognostic variables of ISMs are ice thickness, bedrock topography and ice temperature. The first two of them are the reasonably well-known 2D horizontal fields (Bamber et al., 2001; Layberry and Bamber, 2001; Amante and Eakins, 2009). The 3-D temperature field is much more difficult to estimate, but is also crucial because it is strongly linked to the velocity distribution. The temperature distribution within the ice depends on the past evolution of the ice sheet, in particular on past boundary conditions including surface mass balance and near surface air temperature. The typical time scale of thermal processes is up to 20 kyrs (Huybrechts, 1994), so today's ice temperature is still affected by the temperature increase during the last deglaciation.

To account for this past evolution, we run a long glacialinterglacial spin-up simulation to obtain a realistic present temperature field. To do so, we use present day climatic conditions and apply perturbations deduced from proxy data. The present day atmospheric fields of temperature and precipitation are the same as in the FE09 experiment.

The temperature perturbations with respect to the present day were reconstructed following Huybrechts (2002) based on the GRIP isotopic record (Dansgaard et al., 1993; Johnsen et al., 1997), using a constant slope of $0.42 \% 0^{\circ} \mathrm{C}^{-1}$. These time-dependent and spatially uniform perturbations are used as deviations from present day conditions to force the ISM.
The resulting precipitation perturbations are assumed to follow the temperature evolution as in Eq. 2.

However, the 3-D temperature field obtained after this spin-up procedure corresponds to a topography that is different from the observed one. Consequently, for the sensitivity experiments, we stretch the temperature field to the observed topography in order to obtain the initial state.

Once the 3-D temperature field has been obtained, we tune the various parameters that govern the velocity field by performing dynamic calibration.

These are the four enhancement factors and the $\beta$ coefficient of the basal drag presented in Sect. 2.1. Assuming that after the spin-up procedure the temperature field is realistic, the velocity field will depend on these parameters only. Our target is the surface velocity field measured by radar interferometry (Joughin et al., 2010).

We must stress that for ice streams, it is almost impossible to tune the coefficient $\beta$ of basal drag and the enhancement factors $E_{1}^{\text {SSA }}$ and $E_{3}^{\text {SSA }}$ separately. As explained in Sect. 2.1, the SIA and SSA enhancement factors are not independent and we added a constraint on the relationship between SIA and SSA. This is because the enhancement factors are both equal to 1.0 in the case of isotropic ice, and the stronger the ice anisotropy, the higher the SIA enhancement factors and the lower the SSA enhancement factors (Ma et al., 2010). We chose $E^{\mathrm{SSA}}=0.9$ for $E^{\mathrm{SIA}}=2.0, E^{\mathrm{SSA}}=0.8$ for $E^{\mathrm{SIA}}=3.0$, and $E^{\mathrm{SSA}}=0.63$ for $E^{\mathrm{SIA}}=5.0$. The procedure consists in running short (100 years) simulations in a constant present day climate. We ran a matrix of simulations by varying simultaneously and independently the five parameters already mentioned: the enhancement factors $E_{1}^{\mathrm{SSA}}, E_{3}^{\mathrm{SSA}}, E_{1}^{\mathrm{SIA}}$ and $E_{3}^{\mathrm{SIA}}$, and the $\beta$ coefficient of basal drag. The range tested for the SIA enhancement factors was $1.0<E^{\mathrm{SIA}}<5.0$, corresponding to SSA factors of $1.0>E^{\mathrm{SSA}}>0.63$. The range tested for the $\beta$ coefficient was 500 to $1500 \mathrm{~Pa} . \mathrm{yr} / \mathrm{m}$.

For each set of parameters, we computed mean squared error and standard deviation, in terms of difference between observed and simulated velocities as well as in terms of the respective flux of ice (being the velocity multiplied by the ice depth). The best set of parameters corresponds to the minimum values of mean squared error and standard deviation. Considering that a different set of parameters can give approximately the same statistical scores, we also examined the corresponding mapped velocity amplitudes and distribution histogram and compared then with the observed velocity.

This best set obtained was with:

- Glen cubic law: $E_{3}^{\mathrm{SIA}}=3.0$ and $E_{3}^{\mathrm{SSA}}=0.8$.

- Newtonian finite viscosity: $E_{1}^{\mathrm{SIA}}=1.0$ and $E_{1}^{\mathrm{SSA}}=1.0$.

- Coefficient of basal drag: $\beta=1500 \mathrm{~Pa} \mathrm{yr} \mathrm{m}^{-1}$.

These values are consistent with the findings of Ma et al. (2010), and with the range 3.0-5.0 generally used in the SIA 


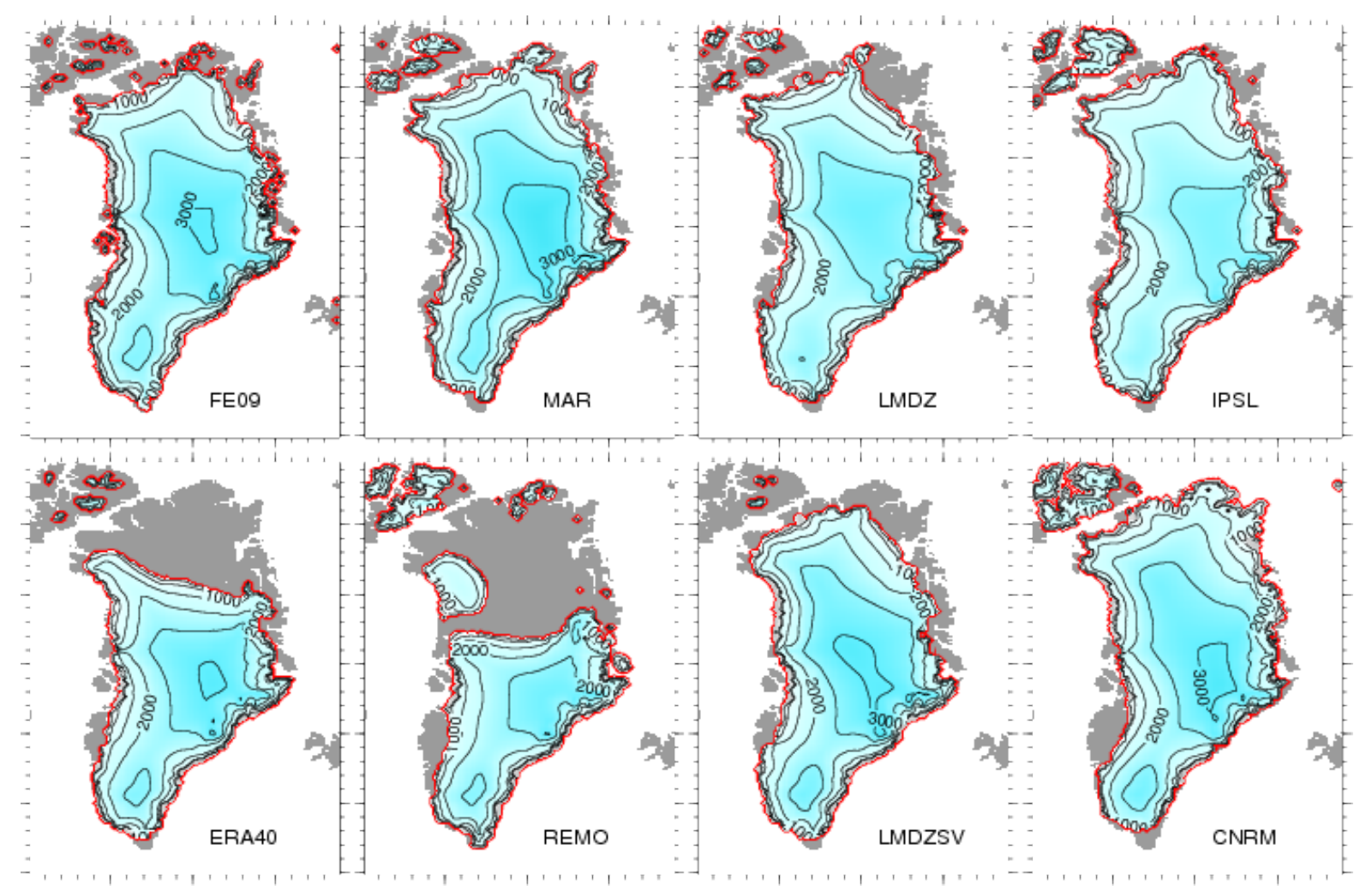

Fig. 5. Simulated ice sheet topography at the end of the 20-kyr constant climate forcing model run.

and Glen flow law case. We used this set of parameters in all further experiments.

This solution is not unique, because we can obtain the same velocity field with more viscous ice streams (lower SSA enhancement factor) and weaker basal drag. It is worth noting that our dynamical calibration is almost independent of the atmospheric forcing fields used. Ice velocity is indeed a diagnostic variable which depends on surface and bedrock topography, 3-D temperature field, basal drag and ice deformation properties, but it does not depend directly on surface mass balance.

Our calibration is, however, impacted by the initial temperature field. Temperature is a prognostic variable and, thus, depends on the past ice sheet evolution, past surface temperature and poorly constrained distribution of geothermal heat flux (Greve, 2005). However, we estimate that this effect is secondary when compared with the impact of the atmospheric field.

Nonetheless, our sensitivity studies indicate that the model results are much more sensitive to surface mass balance than to dynamic parameters: with the FE09 forcing, a doubling of sliding $(\beta / 2)$ induces a $0.1 \%$ reduction in total volume, whereas changing the FE09 forcing for the MAR forcing induces a $9.0 \%$ increase in total volume.

\subsubsection{Sensitivity test procedure}

Having calibrated the dynamical parameters, we compare the responses with the various climate model forcings. We keep the same set of dynamic and mass balance downscaling parameters in all the experiments and change only the atmospheric fields of total precipitation and near surface air temperature provided by the atmospheric models. We then run 20 kyr-long experiments to allow for the ice sheet to stabilise, while keeping the climate constant over time ("glaciological steady state"). Nevertheless, during these simulations, temperature and consequently precipitation, is likely to change, in relation with the elevation changes as described in Sect. 2.3. We do not expect, in this kind of experiment, to reproduce a realistic present day ice sheet because the present day GIS is the result of complex changes of temperature and precipitation during the last thousand years. We do not expect either to provide realistic projections of the future GIS state because we do not perturb the present day climate to take into account the rate of change of temperature and precipitation consequent to changes in concentrations of greenhouse gases. The idea here is to present an idealised configuration depending on a minimal number of parameters. The focus of our analysis in Sect. 3 will, thus, be on the range of relative deviation, from the present reference state obtained with the different atmospheric forcing fields. 
(a)
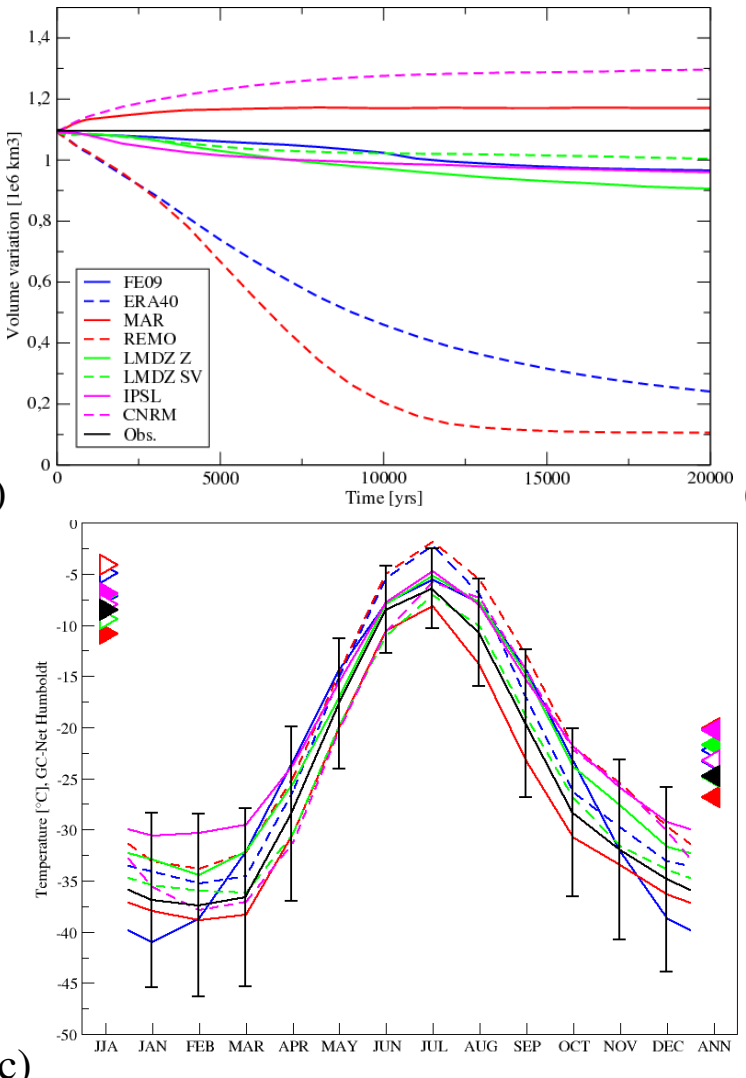

(b)
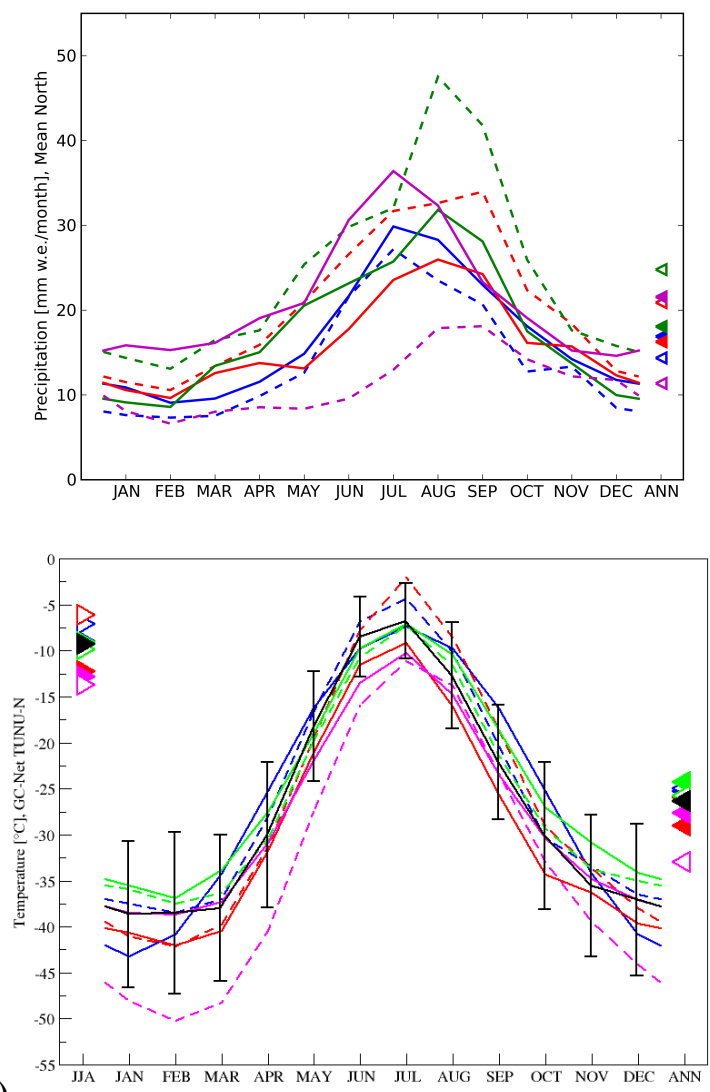

(d)

Fig. 6. (a): North Greenland (latitudes greater than $75^{\circ} \mathrm{N}$ ) simulated ice volume evolution for the steady state model runs shown in Fig. 5 . The regional initial volume corresponds to the observed one. (b): Regional (land mask with latitudes greater than $75^{\circ} \mathrm{N}$ ) monthly mean precipitation for each individual atmospheric forcing, with annual mean values (triangles). (c, d): Station climatology for, respectively, Humboldt and Tunu-N (Steffen et al., 1996), and closest grid point near surface air temperature for each individual atmospheric forcing, with July temperature (left hand triangles) and annual mean temperature (right hand triangles). The black markers stand for the observations (initial regional ice volume and $\mathrm{t} 2 \mathrm{~m}$ stations measurement). Vertical bars are standard deviations from the monthly mean in the observations datasets. Time periods vary, depending on availability.

\section{Results}

\subsection{0 kyr equilibrium simulated topographies}

Figure 5 presents the impact of inter-model climate differences in terms of simulated topography at the end of the run. Differences between simulated topographies and observed topography is available in the Supplement accompanying this paper. A remarkable diversity of simulated topographies is observed. At first sight, the simulated southern part of the ice sheet is more similar than the simulated northern part. In the North, at the end of the simulation, with two models (REMO and ERA40) presenting almost no ice, and at least three models (CNRM, MAR, IPSL) presenting a fully covered area, the range is very broad. The surface height is also very different among the models with an approximate $7 \%$ thickening for MAR in the interior and $8 \%$ thinning with IPSL. In all the simulations, the ice sheet is spreading towards the South West. This common characteristic is due to the ISM's inabil- ity to reproduce fine scale features. The south of Greenland is indeed a very mountainous area characterised by high orographic precipitation and strong slope effects, even in the ice flow dynamics. The $15-\mathrm{km}$ grid is too coarse to reproduce such local effects and specific parameterisations would be needed (Marshall and Clarke, 1999).

To distinguish between the different regional behaviours, we consider three regions: a southern region with latitudes lower than $68^{\circ} \mathrm{N}$, a northern one with latitudes greater than $75^{\circ} \mathrm{N}$, and a central region in between. Specific differences occur mainly in the north and in the south. The central region presents a more complex response and we were not able to identify well-defined specificities. Hence, we discuss mainly the results for the South and North regions. The evolution of the simulated volume for the northern and southern regions is presented in Figs. 6a and 7a, respectively. Except for MAR and CNRM experiments, all models simulate a decrease of ice volume in the north. If we put aside REMO and 
(a)

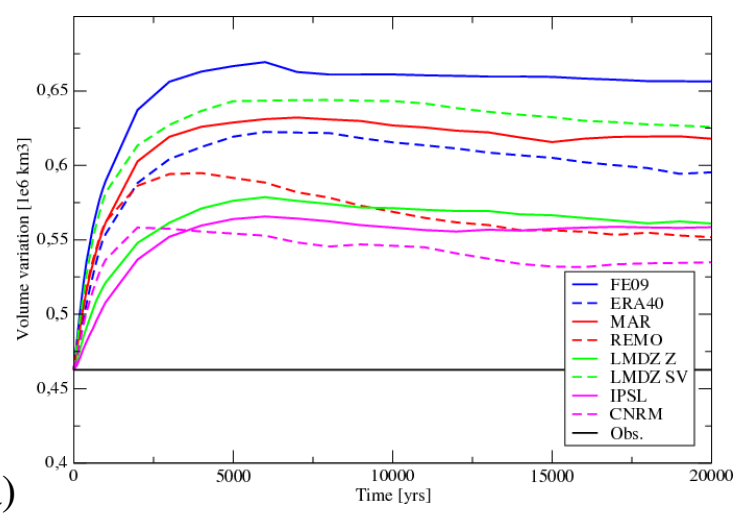

(c)

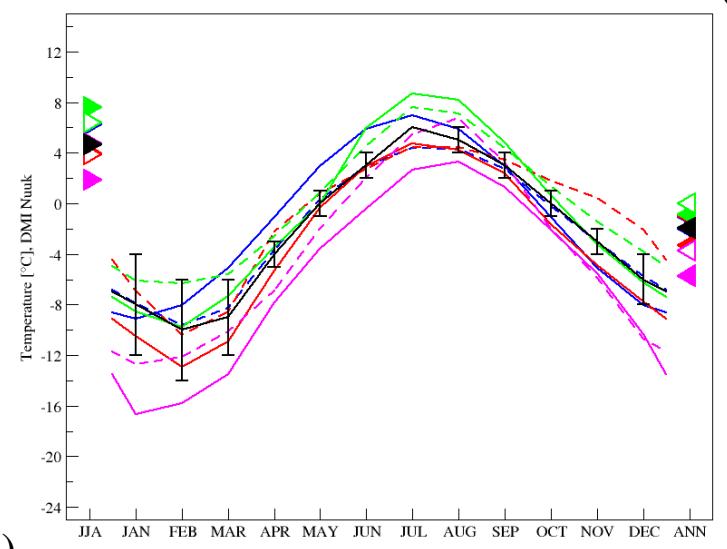

(b)
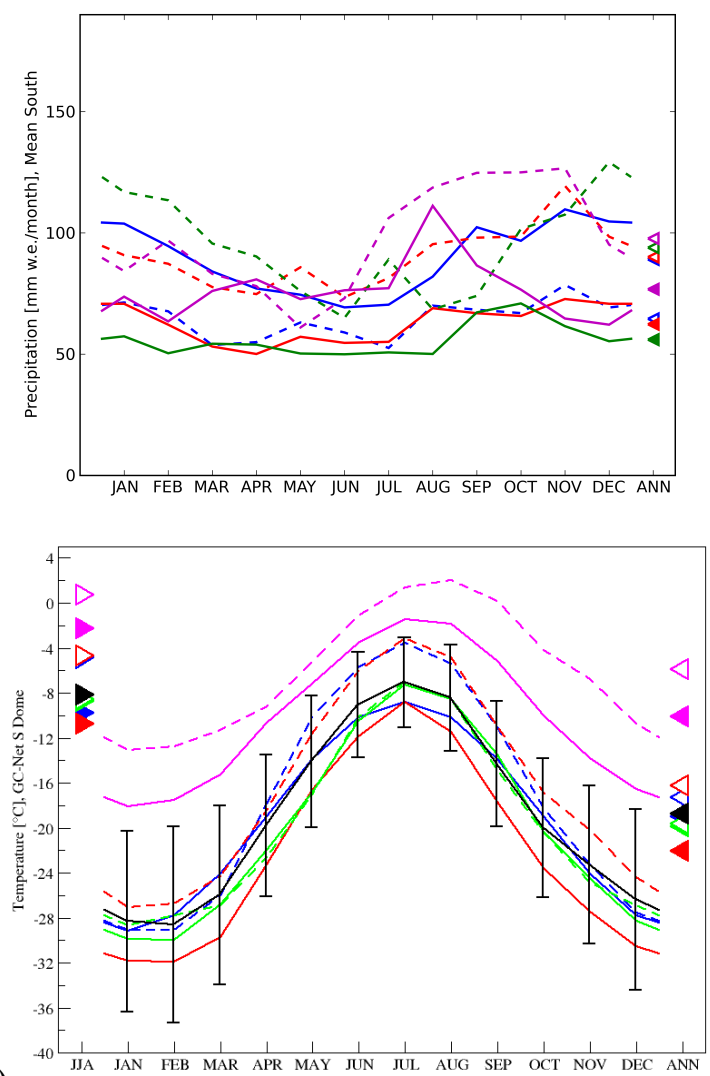

(d)

Fig. 7. (a): South Greenland (latitudes lower than $68^{\circ} \mathrm{N}$ ) simulated ice volume evolution for the steady state model runs shown in Fig. 5 . The regional initial volume corresponds to the observed one. (b): Regional (land mask with latitudes lower than $68^{\circ} \mathrm{N}$ ) monthly mean precipitation for each individual atmospheric forcing, with annual mean values (triangles). (c, d): Station climatology for, respectively, Nuuk (DMI) and South Dome (Steffen et al., 1996), and closest grid point near surface air temperature for each individual atmospheric forcing, with July temperature (left-sided triangles) and annual mean temperature (right-sided triangles). The black markers stand for the observations (initial regional ice volume and $\mathrm{t} 2 \mathrm{~m}$ stations measurement). Vertical bars are standard deviations from the monthly mean in the observations datasets. Time periods vary, depending on availability.

ERA40, which simulate nearly no ice in this region, the volume variation ranges from -0.1 to $+0.1610^{6} \mathrm{~km}^{3}$ in $20 \mathrm{kyrs}$. REMO and ERA40 present the same pattern of retreat probably due to the nudging procedure (von Storch et al., 2000) of the REMO model towards the ERA40 reanalysis. The southern region systematically gains ice volume (Fig. 7a), and the response of the ISM is almost instantaneous, compared to typical evolution time scales, given that $50 \%$ of the final volume variation is generally achieved within a thousand years. The volume simulated by all models reaches a maximum before decreasing slightly due to the precipitation correction. The final volume deviation in this region ranges from 0.05 to $0.1510^{6} \mathrm{~km}^{3}$ in 20 kyrs.

\subsection{Comparison of the atmospheric model results with observations and with the ISM response}

The simulated topographies presented in Fig. 5 and the simulated regional volume evolutions presented in Figs. 6a and 7a highlight the spread of results due to different atmospheric inputs. In this section, we study the simulated volume deviation, by comparing the atmospheric forcing fields on local and regional scales. We take advantage of the presence of weather stations in Greenland to validate the atmospheric near surface temperature fields in the forcing fields at selected points.

Near surface air temperatures for each atmospheric model and for observations are plotted in Figs. 6 and 7 (c, d). Station $2 \mathrm{~m}$ temperature data is evaluated for the automated weather stations (AWS) Humboldt, TUNU-N and South Dome located on the GIS (Steffen et al., 1996) and for the coastal DMI station in Nuuk (Cappelen et al., 2011). Regional mean precipitation is compared in Figs. 6 and 7(b).

The location of the stations is indicated in Fig. 1. At the Humboldt AWS in the northwest of the ice sheet (Fig. 6c), it is apparent that temperatures simulated by ERA40 and REMO are around $5^{\circ} \mathrm{C}$ too high compared to climatological mean observations in July. This is certainly the main reason 
for the rapid ice retreat in this region for those models. The IPSL and LMDZZ models are also slightly warmer than observations in summer, while their seasonal cycle appears to be delayed by a few weeks. MAR is colder than observations throughout the year. There is a spread among models in the boreal winter and the assumption of sinusoidal seasonal variation in FE09 does not give realistic results for the winter. These deficiencies, however, are not relevant for melt and have a lesser impact on the ice mass balance than the summer. At the same time, the IPSL model is too warm in particular during the boreal winter, but also on average, which favours more rapid ice movements and, hence, a rather thin ice sheet in the region despite displaying the highest precipitation of all models.

At the more eastern TUNU-N station, the warm bias of REMO and ERA40 is confirmed. Precipitation is relatively low for the LMDZZ, LMDZSV and CNRM models, but for the latter this bias has no impact on the ice sheet thickness because a strong cold bias from November through July eventually reduces the summer melt.

At Summit (not shown), the spread of model temperatures in the summer has certainly less of an impact due to the absence of melting. LMDZZ and IPSL have the lowest precipitation, resulting in a relatively thinner ice sheet. In contrast, the high precipitation models CNRM and, in particular, MAR have a thicker ice sheet.

At South Dome, the IPSL and CNRM models show strong warm biases, with temperatures $15^{\circ} \mathrm{C}$ higher than other models, and an amplitude of the annual cycle that is too small. At the same time, they have much higher precipitation than the other models. This can be explained by the very coarse resolution of these GCMs that do not capture the high topography of the dome in a satisfactory way. The IPSL model also presents storm-tracks that are slightly shifted southward (Marti et al., 2010), resulting in a wet bias in the south and a dry bias in the north. The rather low ice sheet thickness with LMDZZ can be explained by the low precipitation in the south region in this model. LMDZZ is drier at high elevation than the IPSL probably due to resolution effects (Krinner and Genthon, 1998). However, the local comparison of atmospheric variables is not sufficient to explain the ISM response. The ISM is also influenced by ice flow dynamics, which means that local atmospheric differences at locations other than the three stations considered above may have a regional impact. The following section discusses this issue.

\subsection{Sensitivity to temperature and precipitation}

In the following, we consider the FE09 forcing field as a reference. Given that the FE09 precipitation field by Ettema et al. (2009) is the output from an atmospheric model, we do not claim here that the FE09 is the best atmospheric forcing field and that it is free of biases. The accumulation field computed by the ISM from each atmospheric forcing after downscaling to the ISM grid was compared with the accu- mulation map based on ice/firn cores and coastal precipitation record of Burgess et al. (2010) and van der Veen et al. (2001). The FE09 experiment presents a better agreement than the other forcing fields (see Fig. 8). At this point, it should be noted that the accumulation fields of Burgess et al. (2010) (for ice covered areas) and van der Veen et al. (2001) (for ice free areas) are not suitable for an ISM forcing for paleo experiments and for mid/long-term future projections. The first reason is that atmospheric models generally do not provide accumulation rate as output. A second reason is that although we have some confidence in temperature anomalies (e.g., isotopic content), accumulation is less constrained, being a joint result of both near surface air temperature and precipitation. Differences between each atmospheric forcing field and the FE09 forcing in terms of July temperature and annual mean precipitation on the ISM grid are available in the Supplement.

Considering that ISM dynamical parameters and basal conditions are identical in all simulations, the spread of resulting topographies only results from differences in near surface air temperature and precipitation. In order to distinguish the effects of the two fields, we repeated the previous standard experiments (Table 2), but replaced the precipitation fields by the reference of Ettema et al. (2009). Thus, in the following, the terms "too cold / too warm / too dry / too wet" express anomalies relative to this reference simulation (FE09 forcing).

This approach is different from the simple comparison for all atmospheric models as performed in the previous section because it enables us to compare the atmospheric differences in terms of ice sheet response. For example, a warm bias at an ice stream terminus is likely to have a higher impact than the same bias in a slowly moving area, because of a possible larger ablation zone due to a spreading of the ice. Thus, this section first aims at assessing the impact of the regional differences of climate models from a glaciological point of view. We also aim at determining the key variable (temperature or precipitation) explaining the spread of ISM simulated volumes amongst the atmospheric models. Let us note $d V_{0}$, the volume difference (simulated minus present day observations) at the end of the 20-kyr FE09 simulation. For each atmospheric model $i$ of Table 2, let us note $d V_{i}$, the volume difference of the standard ISM experiment and $d V_{i}^{\prime}$, the volume difference for the simulation where precipitation fields were replaced by the one of Ettema et al. (2009).

Given these anomalies of volume, six cases are possible. The first family of results corresponds to a standard simulated volume anomaly lower than the reference, $d V_{i}<d V_{0}$. This negative anomaly can be due to conditions which are too dry or/and too warm. Three sub-cases can be identified:

- $d V_{i}<d V_{i}^{\prime}<d V_{0}$ : the use of the Ettema et al. (2009) precipitation map increases the simulated volume, which, however, stays below the reference one. The 


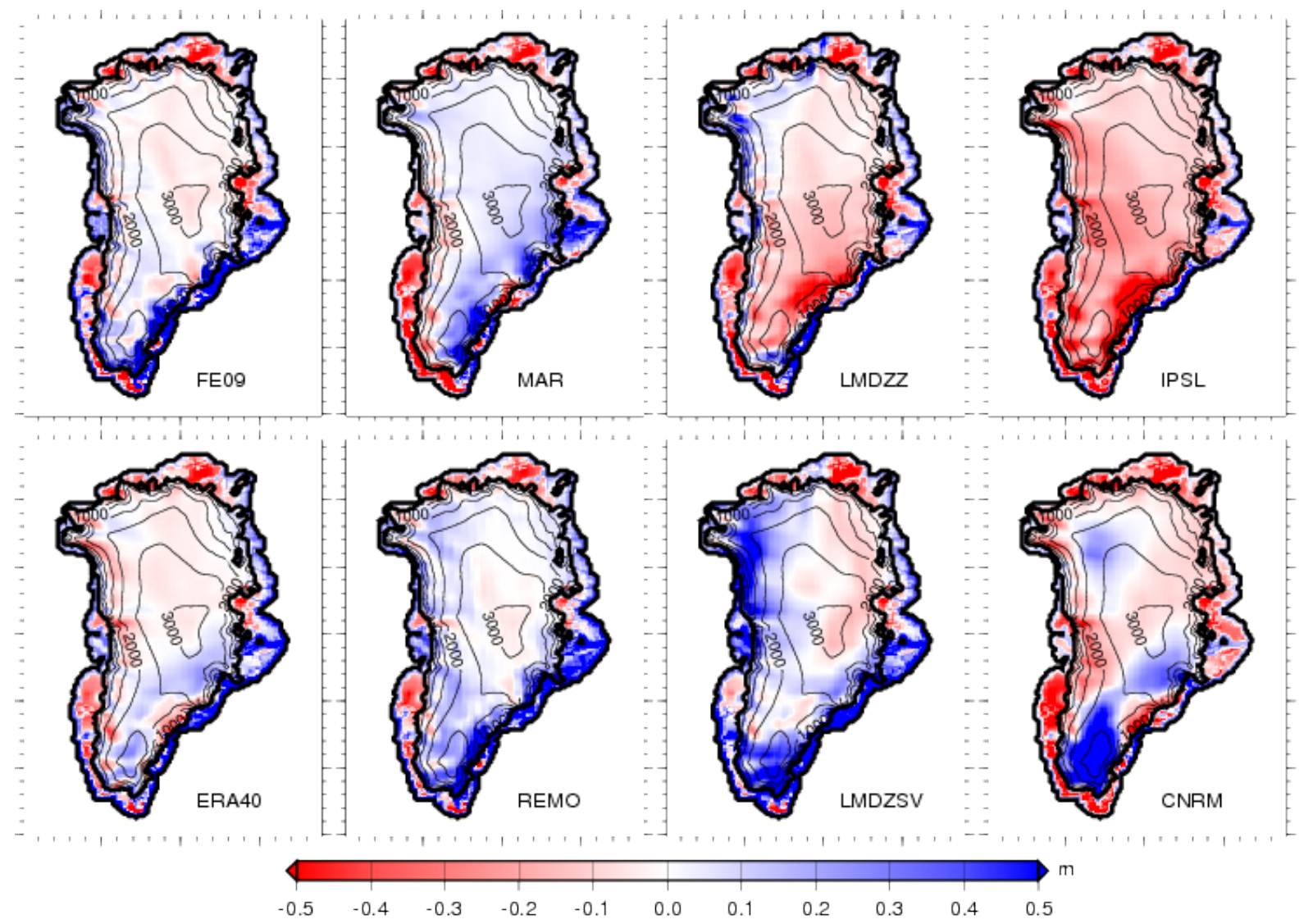

Fig. 8. Difference in annual accumulation between ISM evaluation (after downscaling, snow and rain partitioning and refreezing) and observation based map (Burgess et al., 2010; van der Veen et al., 2001) for each individual atmospheric forcing.

Table 3. Large scale biases of atmospheric forcing fields with respect to FE09 and key variable explaining the deviation of volume (bold).

\begin{tabular}{lll}
\hline $\begin{array}{l}\text { Atmospheric forcing } \\
\text { field }\end{array}$ & $\begin{array}{l}\text { Anomaly in temperature and } \\
\text { precipitation South }\end{array}$ & $\begin{array}{l}\text { Anomaly in temperature } \\
\text { and precipitation North }\end{array}$ \\
\hline ERA40 & Warm & Warm \\
MAR & Warm and dry & Cold and wet \\
REMO & Warm and wet & Warm and wet \\
LMDZZ & Dry & Warm \\
LMDZSV & Warm and wet & Warm and wet \\
IPSL & Cold and dry & Cold and dry \\
CNRM & Very warm and wet & Very cold and dry \\
\hline
\end{tabular}

considered forcing field is consequently too dry $\left(d V_{i}^{\prime}>\right.$ $\left.d V_{i}\right)$ but also too warm $\left(d V_{0}>d V_{i}^{\prime}\right)$.

- $d V_{i}<d V_{0}<d V_{i}^{\prime}$ : as for the previous case, the use of the Ettema et al. (2009) precipitation map increases the simulated volume, but here the final volume anomaly is greater than the reference one. The considered forcing field is consequently too dry $\left(d V_{i}^{\prime}>d V_{i}\right)$ and too cold $\left(d V_{i}^{\prime}>d V_{0}\right)$.

- $d V_{i}^{\prime}<d V_{i}<d V_{0}$ : the simulated volume is even lower with the use of the Ettema et al. (2009) precipitation map. The considered forcing field set is consequently too wet $\left(d V_{i}>d V_{i}^{\prime}\right)$ and too warm $\left(d V_{0}>d V_{i}^{\prime}\right)$. This case indicates a much warmer atmospheric model, because even if it is wetter, the ISM simulated volume is still below the reference volume.

The second family of results corresponds to a simulated volume anomaly greater than the reference, $d V_{i}>d V_{0}$. This positive anomaly can be due to too wet conditions or/and to too cold conditions. Again three sub-cases can be identified: 
(a)
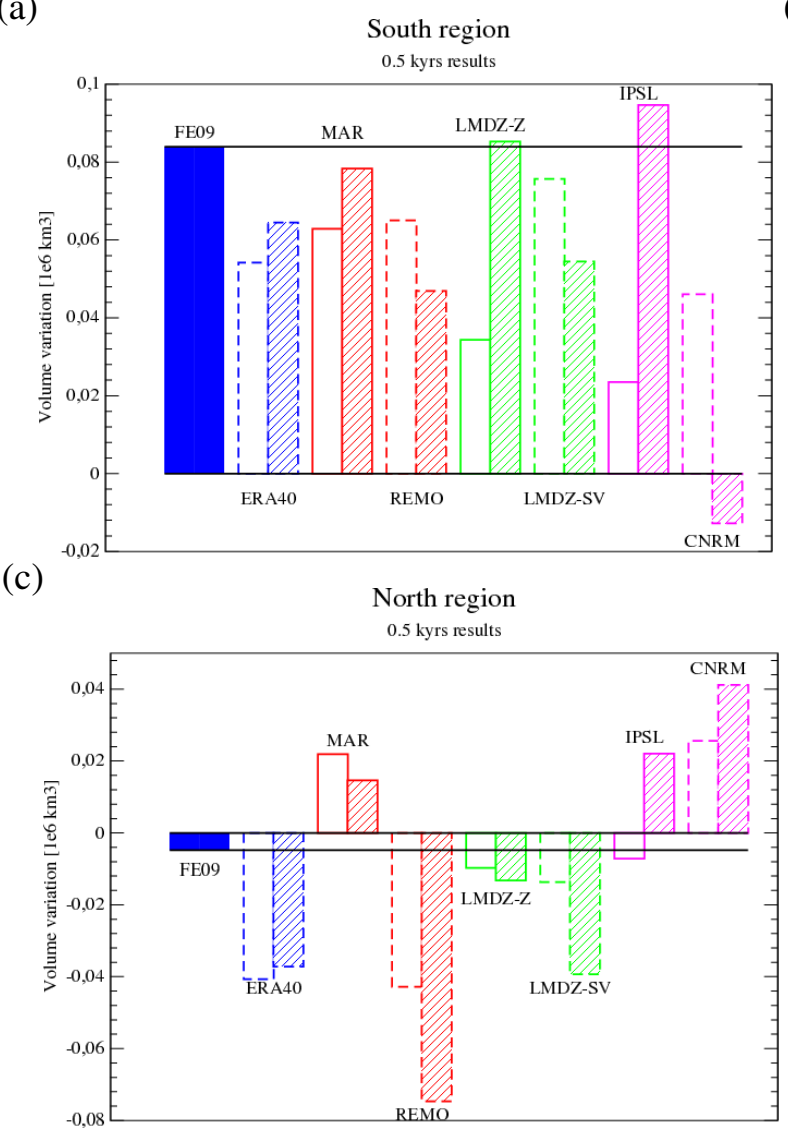

(b)

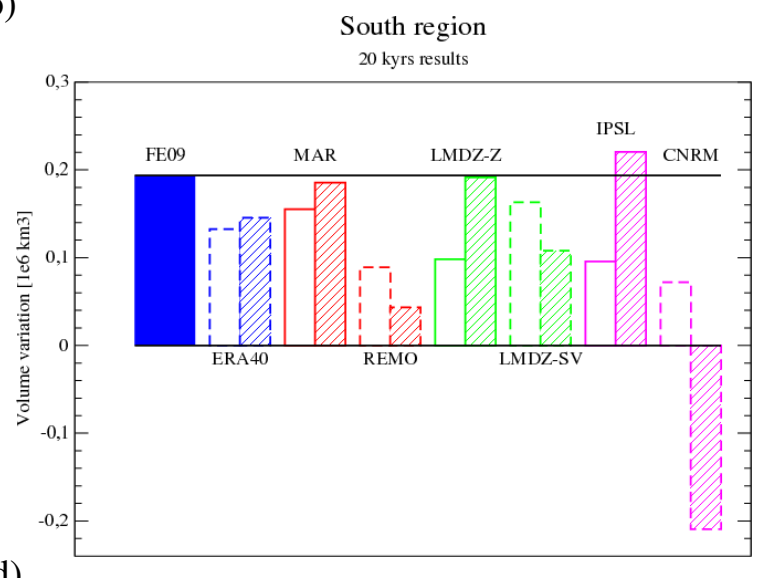

(d)

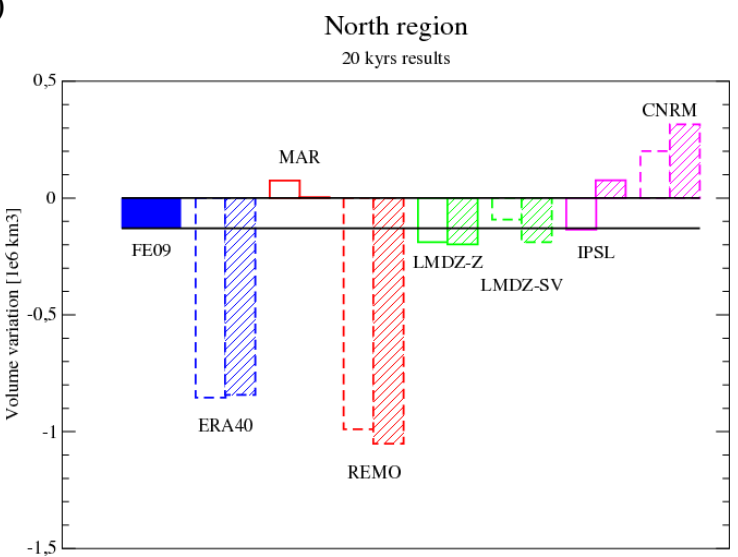

Fig. 9. Regional volume difference (simulated volume minus initial volume, being 1.10 and $0.4610^{6} \mathrm{~km}^{3}$ for north and south, respectively) for each model run. Empty bars correspond to the standard volume difference $\left(d V_{i}\right)$ and hatched bars correspond to the volume difference computed with the precipitation in each model replaced by the Ettema et al. (2009) precipitation map $\left(d V_{i}^{\prime}\right)$. The first solid bar is the simulated reference volume difference $\left(d V_{0}\right.$, FE09). The upper panel corresponds to the south region (latitudes lower than $\left.68^{\circ} \mathrm{N}\right)$ at $0.5 \mathrm{kyr}(\mathbf{a})$ and $20 \mathrm{kyrs}(\mathbf{b})$, and the lower panel corresponds to the north region (latitudes greater than $75^{\circ} \mathrm{N}$ ) at $0.5 \mathrm{kyr}(\mathbf{c})$ and $20 \mathrm{kyrs}(\mathbf{d})$.

- $d V_{i}^{\prime}>d V_{i}>d V_{0}$ : the use of the Ettema et al. (2009) precipitation map increases the simulated volume, augmenting the positive volume anomaly. The considered forcing field is consequently too dry $\left(d V_{i}^{\prime}>d V_{i}\right)$ and too cold $\left(d V_{i}^{\prime}>d V_{0}\right)$. Note that this case suggests that the atmospheric model is strongly cold biased, because even if it is drier, the ISM simulated volume is larger than the reference volume.

- $d V_{i}>d V_{i}^{\prime}>d V_{0}$ : in this case, the use of the Ettema et al. (2009) precipitation map decreases the simulated volume, which still stays above the reference volume anomaly. The considered forcing field is consequently too wet $\left(d V_{i}>d V_{i}^{\prime}\right)$ and too cold $\left(d V_{i}^{\prime}>d V_{0}\right)$.

- $d V_{i}>d V_{0}>d V_{i}^{\prime}:$ as for the previous case, the use of the Ettema et al. (2009) precipitation map decreases the simulated volume, which becomes lower than the reference one. The considered forcing field is consequently too wet $\left(d V_{i}>d V_{i}^{\prime}\right)$ and too warm $\left(d V_{0}>d V_{i}^{\prime}\right)$.
The relative importance of temperature and precipitation on the simulated ice sheet state can be evaluated considering the amplitude of the deviation of the simulated volumes compared with the reference volume. When the value of $d V_{i}^{\prime}$ is close to $d V_{0}$, it means that precipitation is the key factor explaining simulated volume anomaly differences. Temperature in this case is secondary. On the other hand, when $d V_{i}^{\prime}$ and $d V_{i}$ are similar, temperature differences have to be considered as the key factor.

Following this classification and with the simulated volume differences plotted in Fig. 9, we can identify the main bias of the atmospheric models in terms of glaciological response and the key variable for the north and south regions (see Table 3).

The warm models generally retreat in the north, even if they often present a relatively high precipitation anomaly. For instance, the two models presenting a collapse of the northern part, ERA40 and REMO, present a warm bias and the deviation of volume is attributable to temperature only. It 
(a)

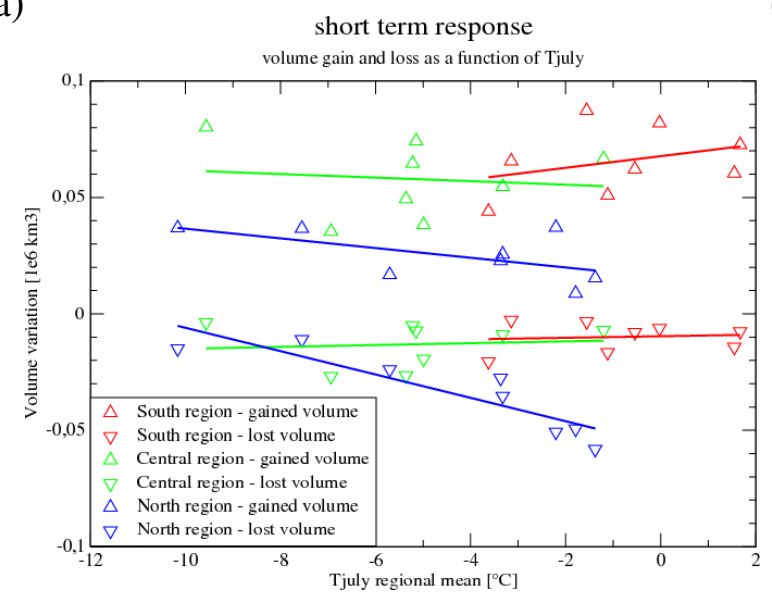

(b)

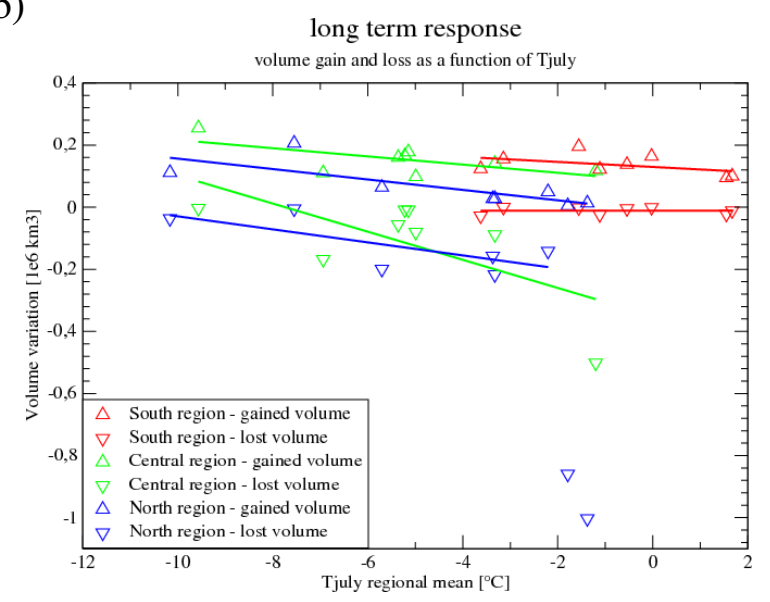

Fig. 10. Volume loss (down-pointing triangle) and gain (up-pointing triangle) as a function of July mean temperature. The tendency lines are also plotted (we omitted the two warmest models, ERA40 and REMO, for the tendency calculation of the north volume loss on the long-term response). The lost (resp. gained) volume is defined as the sum of the negative (resp. positive) thickness variation multiplied by the ISM grid cell area. On the left (a), the volume deviations after a 500-yr simulation and, on the right (b), after a 20-kyr simulation. Each pair of traingles (down and up-pointing) represent a particular atmospheric model.

appears that the range of the simulated volume is mainly attributable to air temperature differences between the forcings in the north ( 3 out of 8 cases for near surface temperature, 0 out of 8 for precipitation) and precipitation differences in the south ( 3 out of 8 for precipitation, 1 out of 8 for near surface temperature).

Hence, the northern region appears to be highly sensitive to air temperature and is more prone to larger volume changes than the southern region. We, therefore, investigate in the next section whether a given warm/cold bias has the same impact on ice volume in the North and in the South.

\subsection{Sensitivity of the ISM to the July temperature}

Figure 10 presents the anomalies of gained and lost volume for the various regions against the mean July temperature in the corresponding region for each of the eight atmospheric forcing fields. We distinguish short-term (500 yrs) and longterm ( $20 \mathrm{kyrs})$ responses in volume anomaly. Each point on the temperature axis corresponds to a specific forcing field. There is a wide spread in the north region temperature among the models: the range of the simulated temperatures over the northern region is $10{ }^{\circ} \mathrm{C}$, while it is less than $5{ }^{\circ} \mathrm{C}$ for the southern region. In the south for both short-term and long-term response, the volume loss, which is close to 0 in most cases, is insensitive to an increase in temperature. The volume gain in this region, however, increases with rising temperatures in the short-term, but decreases slightly with increasing temperatures in the long-term. This means that the south region gains mass with a temperature increase, at greater rates for the short-term response than for the longterm response.
In the north, for both the short-term and long-term responses, an increase in the mean July temperature results in a decrease of volume gain and increase of volume loss. In the long-term response, we can observe a threshold for the July temperature around $-2{ }^{\circ} \mathrm{C}$, above which the volume loss increases drastically. The medium region is intermediate, responding more like the north in the short term and more like the south for the volume loss in the long term.

\subsection{Importance of surface elevation change feedback}

Sea level rise projections generally use complex climate models with fine resolution and/or sophisticated physics. ISMs are not yet included in these models and in this section we want to assess the importance of including the elevation change feedback for the ISM computation of SMB.

For this, the ISM is forced with the 8 atmospheric fields again (Table 2), but without the topographic lapse rate correction. In these conditions, temperature and precipitation remain constant during all of the simulation.

The evolution of the difference of ice volume in the experiment where the elevation change feedback is switched off with respect to the standard correction experiment for the south and north regions is presented in Fig. 11. The two regions show a completely different response.

In the south, all the runs result in a volume closer to observations when we do not take into account the surface elevation change feedback. Considering that the volume anomaly is systematically positive in this region (see Fig. 7a), the experiment without the correction of temperature and precipitation due to surface elevation change presents a better agreement with the initial state. As we already mentioned, due to its resolution, the ISM is not adapted to reproducing steep 
(a)

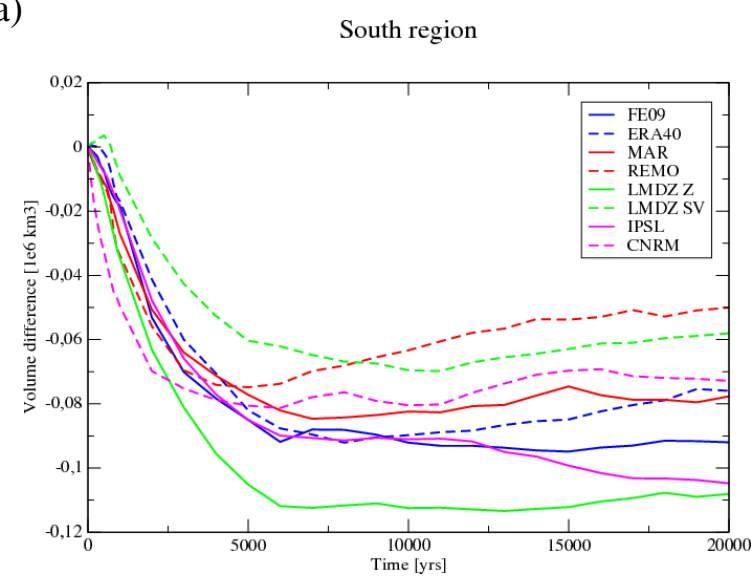

(b)

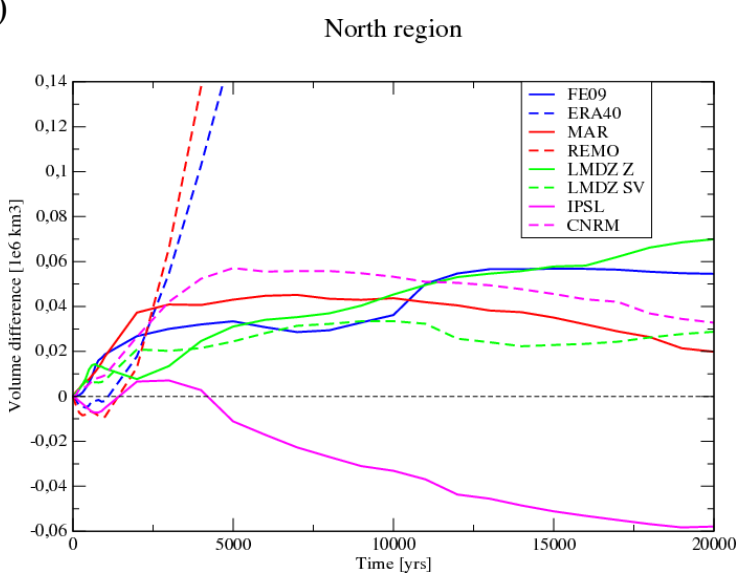

Fig. 11. Evolution of the difference between the experiment in which the surface elevation change feedback on temperature and precipitation is not taken into account, minus the standard correction experiment. On the left (a), the south region (latitudes lower than $68^{\circ} \mathrm{N}$ ) and on the right $(\mathbf{b})$, the north region (latitudes greater than $75^{\circ} \mathrm{N}$ ).

slopes such as those observed in the south. The resulting spread leads to an increase of the elevation in the peripheral area, initially in the ablation zone, but with a high value of precipitation. With the topographic lapse rate correction, the ISM turns this warm and very high precipitation zone into a mild/cold high precipitation zone. The resulting displacement of the equilibrium line is, hence, a direct consequence of the downscaling method and of the resolution of the ISM.

In the north, all the simulations present a bigger ice sheet when the surface elevation change feedback on temperature and precipitation is not taken into account. The only exception is IPSL, i.e., the only model that retreats and has a cold and dry bias. For this model, the dry anomaly causes a general thinning of the ice sheet. A warming and a consequent increase of precipitation is observed when the surface elevation change feedback is taken into account. Two model runs (REMO and ERA40) present a huge difference whether the surface elevation change feedback is taken into account or not. Those two models present a collapse of the north of the GIS (see Fig. 6a) in the standard experiment, but when the surface elevation change feedback is switched off, the ice sheet stabilises and is still present at the end of the run. The surface elevation change feedback on temperature and precipitation accelerates and, thus, accentuates the retreat.

The forcing fields that show a volume increase in the North (MAR and CNRM) produce a slightly bigger volume when the feedback is switched off. This is mainly due to the already cold bias in those forcings (see Sect. 3.3), resulting in an advance of ice over an area which normally is tundra zone.

We can conclude that the surface elevation change feedback on temperature and precipitation is an important driver for the forcing fields with temperature as a predominant variable, accentuating the biases (north case). However, when precipitation is the driver, this feedback tends to reduce the deviation (south case). It also appears that we cannot discard this feedback for simulations lasting more than a thousand years.

\section{Conclusions}

In the face of uncertainties on future climate, we need to develop tools to predict the coupled climate-ice sheet evolution for the coming centuries. The first step in this development should be to validate the uncoupled approach and to do so, we have performed here a sensitivity study of an ice sheet model (ISM) to atmospheric forcing fields. We have applied several atmospheric forcing fields to an ISM in climatic steady state experiments. We have shown major discrepancies in the simulated ice sheets resulting from the different atmospheric forcing fields due to the tendency of the ISM to integrate the biases in the atmospheric forcings. Apart from the numerical and physical differences among the climate models, the model resolution also plays a role in explaining the range of model results. Using the same interpolation method for all forcing fields, we do not find a systematic difference between regional climate models and global GCMs. Nonetheless, some of the models seem to be inappropriate for absolute forcing. For these models, we suggest the use of an anomaly method, in which the ISM is forced with the best available present day climatology plus anomalies computed by the climate model as a perturbation, instead.

Although July temperature seems to be important for the ISM behaviour, in particular in the northern part of the GIS, precipitation may also play an important role, particularly in the south. We have shown that the north of Greenland is more sensitive to temperature anomalies than the south and we suspect that major changes are likely to occur there in a warmer climate. The south seems to be relatively stable and almost 
insensitive to July temperature, as in the works of Stone et al. (2010); Greve et al. (2011); Born and Nisancioglu (2011); Fyke et al. (2011). This southern stability is not reflected, however, in the works of Cuffey and Marshall (2000); OttoBliesner et al. (2006); Robinson et al. (2010). The precise geographical definition of these regions characterised by different sensitivities to climate may vary depending on the SMB calculation used. In particular, the PDD method may increase the changes in a warmer climate compared with more physically based calculation (van de Wal , 1996). The bedrock map used can also greatly affect the results (Stone et al., 2010).

The surface elevation change feedback on temperature and precipitation can play an important role in long simulations over several thousand years, even though it is of secondary order compared with atmospheric model biases. While the most common way to downscale surface temperature forcing fields from climate model to ISM is using a relatively unconstrained topographic lapse rate, specific experiments have to be performed.

The current ISM is unable to accurately reproduce the southern ice sheet topography because it does not take into account the very fine scale processes taking place in this region. To improve on this, in addition to a finer ISM grid, very fine resolution atmospheric forcing fields and better downscaling techniques are required, such as those proposed by Gallée et al. (2011).

\section{Supplementary material related to this article is available online at: http://www.the-cryosphere.net/6/999/ 2012/tc-6-999-2012-supplement.pdf.}

Acknowledgements. We thank CISM for providing the datasets of Shapiro and Ritzwoller (2004); Joughin et al. (2010); Burgess et al. (2010); van der Veen et al. (2001). Janneke Ettema, Jan van Angelen and Michiel van den Broeke (IMAU, Utrecht University) are thanked for providing RACMO2 climate fields. We thank Konrad Steffen and the DMI for providing temperature data for the Greenland weather stations. Aurélien Quiquet is supported by the ANR project NEEM-France. NEEM is directed and organized by the Center of Ice and Climate at the Niels Bohr Institute and US NSF, Office of Polar Programmes. It is supported by funding agencies and institutions in Belgium (FNRS-CFB and FWO), Canada (NRCan/GSC), China (CAS), Denmark (FIST), France (IPEV, CNRS/INSU, CEA and ANR), Germany (AWI), Iceland (RannIs), Japan (NIPR), Korea (KOPRI), The Netherlands (NWO/ALW), Sweden (VR), Switzerland (SNF), UK (NERC) and the USA (US NSF, Office of Polar Programs). Heinz-Jürgen Punge is supported by the European Commission FP7 project 226520 COMBINE and the ANR project NEEM-France. This work was supported by funding from the ice2sea programme from the $\mathrm{Eu}-$ ropean Union 7th Framework Programme, grant number 226375. Ice2sea contribution number ice2sea066. All (or most of) the computations presented in this paper were performed using the
CIMENT infrastructure (https://ciment.ujf-grenoble.fr), which is supported by the Rhône-Alpes region (GRANT CPER07_13 CIRA: http://www.ci-ra.org).

Edited by: M. van den Broeke

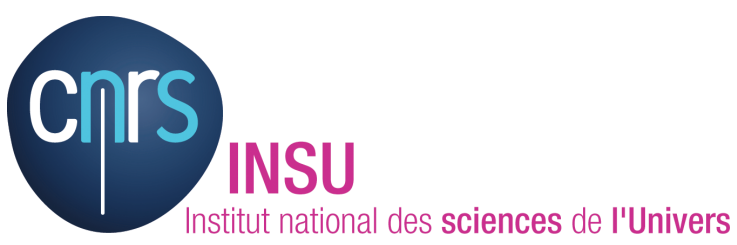

The publication of this article is financed by CNRS-INSU.

\section{References}

Álvarez-Solas, J., Charbit, S., Ramstein, G., Paillard, D., Dumas, C., Ritz, C., and Roche, D. M.: Millennial-scale oscillations in the Southern Ocean in response to atmospheric CO2 increase, Global Planet. Change, 76, 128-136, doi:10.1016/j.gloplacha.2010.12.004, 2011.

Álvarez-Solas, J., Montoya, M., Ritz, C., Ramstein, G., Charbit, S., Dumas, C., Nisancioglu, K., Dokken, T., and Ganopolski, A.: Heinrich event 1: an example of dynamical ice-sheet reaction to oceanic changes, Clim. Past, 7, 1297-1306, doi:10.5194/cp7-1297-2011, 2011.

Amante, C. and Eakins, B.: ETOPO1 1 Arc-Minute Global Relief Model: Procedures, Data Sources and Analysis, NOAA Technical Memorandum NESDIS NGDC-24, p. 19, 2009.

Arthern, R. J. and Gudmundsson, G. H.: Initialization of ice-sheet forecasts viewed as an inverse Robin problem, J. Glaciol., 56, 527-533, doi:10.3189/002214310792447699, 2010.

Bamber, J. L., Layberry, R. L., and Gogineni, S. P.: A new ice thickness and bed data set for the Greenland ice sheet 1. Measurement, data reduction, and errors, J. Geophys. Res., 106, 33773-33780, doi:10.1029/2001JD900054, 2001.

Bintanja, R., van de Wal, R. S. W. and Oerlemans, J.: Global ice volume variations through the last glacial cycle simulated by a 3-D ice-dynamical model, Quatern. Int., 95-96, 11-23, doi:10.1016/S1040-6182(02)00023-X, 2002.

Born, A. and Nisancioglu, K. H.: Melting of Northern Greenland during the last interglacial, The Cryosphere Discuss., 5, 35173539, doi:10.5194/tcd-5-3517-2011, 2011.

Brun, E., David, P., Sudul, M., and Brunot, G.: A numerical model to simulate snow-cover stratigraphy for opera tional avalanche forecasting, J. Glaciol., 38, 13-22, 1992.

Bueler, E. and Brown, J.: Shallow shelf approximation as a "sliding law" in a thermomechanically coupled ice sheet model, J. Geophys. Res., 114, F03008, doi:10.1029/2008JF001179, 2009.

Burgess, E. W., Forster, R. R., Box, J. E., Mosley-Thompson, E., Bromwich, D. H., Bales, R. C., and Smith, L. C.: A spatially calibrated model of annual accumulation rate on the Greenland Ice Sheet (1958-2007), J. Geophys. Res.-Earth, 115, F02004, doi:10.1029/2009JF001293, 2010. 
Cappelen, J., Laursen, E. V., Jørgensen, P. V., and Kern-Hansen, C.: DMI Monthly Climate Data Collection 1768-2009, Denmark, The FaroeIslands and Greenland, DMI Technical Report, 10-05, 2011.

Charbit, S., Ritz, C., and Ramstein, G.: Simulations of Northern Hemisphere ice-sheet retreat: sensitivity to physical mechanisms involved during the Last Deglaciation, Quatern. Sci. Rev., 21, 243-265, doi:10.1016/S0277-3791(01)00093-2, 2002.

Charbit, S., Ritz, C., Philippon, G., Peyaud, V., and Kageyama, M.: Numerical reconstructions of the Northern Hemisphere ice sheets through the last glacial-interglacial cycle, Clim. Past, 3, 15-37, doi:10.5194/cp-3-15-2007, 2007.

Cuffey, K. M. and Marshall, S. J.: Substantial contribution to sealevel rise during the last interglacial from the Greenland ice sheet, Nature, 404, 591-594, 2000.

Dansgaard, W., Johnsen, S. J., Clausen, H. B., Dahl-Jensen, D., Gundestrup, N. S., Hammer, C. U., Hvidberg, C. S., Steffensen, J. P., Sveinbjornsdottir, A. E., and Jouzel, J.: Evidence for general instability of past climate from a 250-kyr ice-core record, Nature, 364, 218-220, 1993.

Driesschaert, E., Fichefet, T., Goosse, H., Huybrechts, P., Janssens, I., Mouchet, A., Munhoven, G., Brovkin, V., and Weber, S. L.: Modeling the influence of Greenland ice sheet melting on the Atlantic meridional overturning circulation during the next millennia, Geophys. Res. Lett., 34, L10707, doi:10.1029/2007GL029516, 2007.

Ettema, J., van den Broeke, M. R., van Meijgaard, E., van de Berg, W. J., Bamber, J. L., Box, J. E., and Bales, R. C.: Higher surface mass balance of the Greenland ice sheet revealed by highresolution climate modeling, Geophys. Res. Lett., 36, L12501, doi:10.1029/2009GL038110, 2009.

Fausto, R. S., Ahlstrøm, A. P., van As, D., Bøggild, C. E., and Johnsen, S. J.: A new present-day temperature parameterization for Greenland, J. Glaciol., 55, 95-105, doi:10.3189/002214309788608985, 2009.

Fausto, R. S., Ahlstrøm, A. P., van As, D., Johnsen, S. J., Langen, P. L., and Steffen, K.: Improving surface boundary conditions with focus on coupling snow densification and meltwater retention in large-scale ice-sheet models of Greenland, J. Glaciol., 55, 869878, doi:10.3189/002214309790152537, 2009.

Fettweis, X.: Reconstruction of the 1979-2006 Greenland ice sheet surface mass balance using the regional climate model MAR, The Cryosphere, 1, 21-40, doi:10.5194/tc-1-21-2007, 2007.

Fettweis, X., Tedesco, M., van den Broeke, M., and Ettema, J.: Melting trends over the Greenland ice sheet (1958-2009) from spaceborne microwave data and regional climate models, The Cryosphere, 5, 359-375, doi:10.5194/tc-5-359-2011, 2011.

Franco, B., Fettweis, X., Erpicum, M., and Nicolay, S.: Present and future climates of the Greenland ice sheet according to the IPCC AR4 models, Clim. Dynam., 36, 1897-1918, doi:10.1007/s00382-010-0779-1, 2011.

Fyke, J. G., Weaver, A. J., Pollard, D., Eby, M., Carter, L., and Mackintosh, A.: A new coupled ice sheet/climate model: description and sensitivity to model physics under Eemian, Last Glacial Maximum, late Holocene and modern climate conditions, Geosci. Model Dev., 4, 117-136, doi:10.5194/gmd-4-1172011, 2011.
Gallée, H., Guyomarc'h, G., and Brun, E.: Impact of snow drift on the Antarctic ice sheet surface mass balance: possible sensitivity to snow-surface properties, Bound.-Lay. Meteorol., 99, 1-19, 2001.

Gallée, H., Agosta, C., Gential, L., Favier, V., and Krinner, G.: A downscaling approach toward high-resolution surface mass balance over Antarctica, Surv. Geophys., 32, 507-518, doi:10.1007/s10712-011-9125-3, 2011.

Graversen, R. G., Drijfhout, S., Hazeleger, W., van de Wal, R., Bintanja, R., and Helsen, M.: Greenland's contribution to global sealevel rise by the end of the 21 st century, Clim. Dynam., 37, 14271442, 2010.

Greve, R.: Application of a polythermal three-dimensional ice sheet model to the Greenland ice sheet: Response to steadystate and transient climate scenarios, J. Climate, 10, 901-918, doi:10.1175/1520-0442(1997)010<0901:AOAPTD>2.0.CO;2, 1997.

Greve, R.: Relation of measured basal temperatures and the spatial distribution of the geothermal heat flux for the Greenland ice sheet, Ann. Glaciol., 42, 424-432, 2005.

Greve, R., Saito, F., and Abe-Ouchi, A.: Initial results of the SeaRISE numerical experiments with the models SICOPOLIS and IcIES for the Greenland ice sheet, Ann. Glaciol., 52, 23-30, 2011.

Hebeler, F., Purves, R. S., and Jamieson, S. S. R.: The impact of parametric uncertainty and topographic error in ice-sheet modelling, J. Glaciol., 54, 899-919, 2008.

Helsen, M. M., van de Wal, R. S. W., van den Broeke, M. R., van de Berg, W. J., and Oerlemans, J.: Coupling of climate models and ice sheet models by surface mass balance gradients: application to the Greenland Ice Sheet, The Cryosphere, 6, 255-272, doi:10.5194/tc-6-255-2012, 2012.

Hourdin, F., Musat, I., Bony, S., Braconnot, P., Codron, F., Dufresne, J., Fairhead, L., Filiberti, M., Friedlingstein, P., Grandpeix, J., Krinner, G., Levan, P., Li, Z., and Lott, F.: The LMDZ4 general circulation model: climate performance and sensitivity to parametrized physics with emphasis on tropical convection, Clim. Dynam., 27, 787-813, doi:10.1007/s00382-006-0158-0, 2006.

Hubbard, A., Bradwell, T., Golledge, N., Hall, A., Patton, H., Sugden, D., Cooper, R., and Stoker, M.: Dynamic cycles, ice streams and their impact on the extent, chronology and deglaciation of the British-Irish ice sheet, Quaternary Sci. Rev., 28, 758-776, 2009.

Hutter, K.: Theoretical glaciology: material science of ice and the mechanics of glaciers and ice sheets, Springer, Reidel Publishing Company, Dordrecht, The Netherlands, 1983.

Huybrechts, P.: The present evolution of the Greenland ice sheet: an assessment by modelling, Global Planet. Change, 9, 39-51, doi:10.1016/0921-8181(94)90006-X, 1994.

Huybrechts, P.: Sea-level changes at the LGM from ice-dynamic reconstructions of the Greenland and Antarctic ice sheets during the glacial cycles, Quatern. Sci. Rev., 21, 203-231, doi:10.1016/S0277-3791(01)00082-8, 2002.

Jacob, D. and Podzun, R.: Sensitivity studies with the regional climate model REMO, Meteorol. Atmos. Phys., 63, 119-129, doi:10.1007/BF01025368, 1997. 
Janssens, I. and Huybrechts, P.: The treatment of meltwater retardation in mass-balance paramete rizations of the Greenland ice sheet, Ann. Glaciol., 31, 133-140, 2000.

Johnsen, S. J., Clausen, H. B., Dansgaard, W., Gundestrup, N. S., Hammer, C. U., Andersen, U., Andersen, K. K., Hvidberg, C. S., Dahl-Jensen, D., Steffensen, J. P., Shoji, H., Sveinbjörnsdóttir, Á. E., White, J., Jouzel, J., and Fishe, D.: The $\delta^{18}$ O record along the Greenland Ice Core Project deep ice core and the problem of possible Eemian climatic instability, J. Geophys. Res., 102, 26397-26410, doi:10.1029/97JC00167, 1997.

Joughin, I., Smith, B. E., Howat, I. M., Scambos, T., and Moon, T.: Greenland flow variability from icesheet-wide velocity mapping, J. Glaciol., 56, 415-430, doi:10.3189/002214310792447734, 2010.

Kageyama, M. and Valdes, P. J.: Impact of the North American ice-sheet orography on the Last Glacial Maximum eddies and snowfall, Geophys. Res. Lett., 27, 1515-1518, doi:10.1029/1999GL011274, 2000.

Kageyama, M., Charbit, S., Ritz, C., Khodri, M., and Ramstein, G.: Quantifying ice-sheet feedbacks during the last glacial inception, Geophys. Res. Lett., 31, 24203, 2004.

Kirchner, N., Greve, R., Stroeven, A. P., and Heyman, J.: Paleoglaciological reconstructions for the Tibetan Plateau during the last glacial cycle: evaluating numerical ice sheet simulations driven by GCM-ensembles, Quaternary Sci. Rev., 30, 248-267, 2011.

Krinner, G. and Genthon, C.: GCM simulations of the Last Glacial Maximum surface climate of Greenland and Antarctica, Clim. Dynam., 14, 741-758, doi:10.1007/s003820050252, 1998.

Krinner, G. and Genthon, C.: Altitude dependence of the ice sheet surface climate, Geophys. Res. Lett., 26, 2227-2230, doi:10.1029/1999GL900536, 1999.

Layberry, R. L. and Bamber, J. L.: A new ice thickness and bed data set for the Greenland ice sheet 2. Relationship between dynamics and basal topography, J. Geophys. Res., 106, 33781-33788, doi:10.1029/2001JD900053, 2001.

Lefebre, F., Gallée, H., van Ypersele, J., and Huybrechts, P.: Modelling of large-scale melt parameters with a regional climate model in south Greenland during the 1991 melt season, Ann. Glaciol., 35, 391-397, doi:10.3189/172756402781816889, 2002.

Letréguilly, A., Reeh, N., and Huybrechts, P.: The Greenland ice sheet through the last glacial-interglacial cycle, Global Planet. Change, 4, 385-394, doi:10.1016/0921-8181(91)90004-G, 1991.

Lliboutry, L. and Duval, P.: Various isotropic and anisotropic ices found in glaciers and polar ice caps and their corresponding rheologies, Ann. Geophys., 3, 207-224, 1985, http://www.ann-geophys.net/3/207/1985/.

Ma, Y., Gagliardini, O., Ritz, C., Gillet-Chauvet, F., Durand, G., and Montagnat, M.: Enhancement factors for grounded ice and ice shelves inferred from an anisotropic ice-flow model, J. Glaciol., 56, 805-812, 2010.

MacAyeal, D. R.: Large-scale ice flow over a viscous basal sediment: theory and application to ice stream B, Antarctica, J. Geophys. Res., 94, 4071-4087, doi:10.1029/JB094iB04p04071, 1989.

Marshall, S. J. and Clarke, G. K. C.: Ice sheet inception: subgrid hypsometric parameterization of mass balance in an ice sheet model, Clim. Dynam., 15, 533-550, doi:10.1007/s003820050298, 1999.

Marsiat, I.: Simulation of the Northern Hemisphere continental ice sheets over the last glacial-interglacial cycle: experiments with a latitude-longitude vertically integrated ice sheet model coupled to zonally averaged climate model, Paleoclimates, 1, 59-98, 1994.

Marti, O., Braconnot, P., Dufresne, J., Bellier, J., Benshila, R., Bony, S., Brockmann, P., Cadule, P., Caubel, A., Codron, F., Noblet, N., Denvil, S., Fairhead, L., Fichefet, T., Foujols, M., Friedlingstein, P., Goosse, H., Grandpeix, J., Guilyardi, E., Hourdin, F., Idelkadi, A., Kageyama, M., Krinner, G., LÄvy, C., Madec, G., Mignot, J., Musat, I., Swingedouw, D., and Talandier, C.: Key features of the IPSL ocean atmosphere model and its sensitivity to atmospheric resolution, Clim. Dynam., 34, 1-26, doi:10.1007/s00382-009-0640-6, 2010.

Meehl, G. A., Stocker, T. F., Collins, W. D., Friedlingstein, P., Gaye, A. T., Gregory, J. M., Kitoh, A., Knutti, R., Murphy, J. M., Noda, A., Raper, S. C. B., Watterson, I. G., Weaver, A. J., and Zhao, Z.-C.: Global climate projections, in: Climate Change 2007: The Physical Science Basis. Contribution of Working Group I to the Fourth Assessment Report of the Intergovernmental Panel on Climate Change, (edited by: Solomon, S., Qin, D., Manning, M., Chen, Z., Marquis, M., Averyt, K. B., Tignor, M., and Miller, H. L.), Cambridge Univ. Press, 2007.

Otto-Bliesner, B. L., Marshall, S. J., Overpeck, J. T., Miller, G. H., and $\mathrm{Hu}, \mathrm{A} .:$ Simulating Arctic climate warmth and icefield retreat in the last interglaciation, Science, 311, 1751-1753, 2006.

Peyaud, V., Ritz, C., and Krinner, G.: Modelling the Early Weichselian Eurasian Ice Sheets: role of ice shelves and influence of ice-dammed lakes, Clim. Past, 3, 375-386, doi:10.5194/cp-3375-2007, 2007.

Philippon, G., Ramstein, G., Charbit, S., Kageyama, M., Ritz, C., and Dumas, C.: Evolution of the Antarctic ice sheet throughout the last deglaciation: a study with a new coupled climate - north and south hemisphere ice sheet model, Earth Planet. Sci. Lett., 248, 750-758, doi:10.1016/j.epsl.2006.06.017, 2006.

Pollard, D.: A retrospective look at coupled ice sheet-climate modeling, Clim. Change, 100, 173-194, doi:10.1007/s10584-0109830-9, 2010.

Punge, H. J., Gallée, H., Kageyama, M., and Krinner, G.: Modelling snow accumulation on Greenland in Eemian, glacial inception and modern climates in a GCM, Clim. Past Discuss., 8, 15231565, doi:10.5194/cpd-8-1523-2012, 2012.

Reeh, N.: Parameterization of melt rate and surface temperature on the Greenland Ice Sheet, Polarforschung, 59, 113-128, 1991.

Ridley, J., Gregory, J., Huybrechts, P., and Lowe, J.: Thresholds for irreversible decline of the Greenland ice sheet, Clim. Dynam., 35, 1049-1057, doi:10.1007/s00382-009-0646-0, 2010.

Ridley, J. K., Huybrechts, P., Gregory, J. M., and Lowe, J. A.: Elimination of the Greenland Ice Sheet in a high $\mathrm{CO}_{2}$ climate, J. Climate, 18, 3409-3427, doi:10.1175/JCLI3482.1, 2005.

Ritz, C., Lliboutry, L., and Rado, C.: Analysis of a 870 m deep temperature profile at Dome C, Ann. Glaciol., 3, 284-289, 1983.

Ritz, C., Fabre, A., and Letréguilly, A.: Sensitivity of a Greenland ice sheet model to ice flow and ablation parameters: consequences for the evolution through the last climatic cycle, Clim. Dynam., 13, 11-23, doi:10.1007/s003820050149, 1997.

Ritz, C., Rommelaere, V., and Dumas, C.: Modeling the evolution of Antarctic ice sheet over the last 420,000 years: Implications 
for altitude changes in the Vostok region, J. Geophys. Res., 106, 31943-31964, 2001.

Robinson, A., Calov, R., and Ganopolski, A.: Greenland ice sheet model parameters constrained using simulations of the Eemian Interglacial, Clim. Past, 7, 381-396, doi:10.5194/cp-7-381-2011, 2011.

Salas-Mélia, D., Chauvin, F., Déqué, M., Douville, H., Gueremy, J. F., Marquet, P., Planton, S., Royer, J. F., and Tyteca, S.: Description and validation of the CNRM-CM3 global coupled model, CNRM working note, 103, 36 pp., 2005.

Shapiro, N. M. and Ritzwoller, M. H.: Inferring surface heat flux distributions guided by a global seismic model: particular application to Antarctica, Earth Planet. Sci. Lett., 223, 213-224, doi:10.1016/j.eps1.2004.04.011, 2004.

Sjolte, J., Hoffmann, G., Johnsen, S., Vinther, B., MassonDelmotte, V., and Sturm, C.: Modeling the water isotopes in Greenland precipitation 1959-2001 with the mesoscale model REMO-iso, J. Geophys. Res., 116, D18105, doi:10.1029/2010JD015287, 2011.

Solgaard, A. M. and Langen, P. L.: Multistability of the Greenland ice sheet and the effects of an adaptive mass balance formulation, Clim. Dynam., doi:10.1007/s00382-012-1305-4, in press, 2012.

Steffen, K., Box, J., and Abdalati, W.: Greenland Climate Network: GC-Net, Special report on glaciers, ice sheets and volcanoes, (edited by: Colbeck, W. C.), Report 96-27103, 98-103, 1996.

Stokes, C. R. and Clark, C. D.: Geomorphological criteria for identifying Pleistocene ice streams, Ann. Glaciol., 28, 67-74, 1999.

Stone, E. J., Lunt, D. J., Rutt, I. C., and Hanna, E.: Investigating the sensitivity of numerical model simulations of the modern state of the Greenland ice-sheet and its future response to climate change, The Cryosphere, 4, 397-417, doi:10.5194/tc-4-397-2010, 2010.

Sturm, K., Hoffmann, G., Langmann, B., and Stichler, W.: Simulation of $\delta^{18} \mathrm{O}$ in precipitation by the regional circulation model REMOiso, Hydrol. Proces., 19, 3425-3444, doi:10.1002/hyp.5979, 2005.

Swingedouw, D., Fichefet, T., Huybrechts, P., Goosse, H., Driesschaert, E., and Loutre, M.: Antarctic ice-sheet melting provides negative feedbacks on future climate warming, Geophys. Res. Lett., 35, L17705, doi:10.1029/2008GL034410, 2008.

Tarasov, L. and Peltier, W. R.: Greenland glacial history and local geodynamic consequences, Geophys. J. Int., 150, 198-229, doi:10.1046/j.1365-246X.2002.01702.x, 2002.
Uppala, S. M., Kållberg, P. W., Simmons, A. J., Andrae, U., Bechtold, V. D. C., Fiorino, M., Gibson, J. K., Haseler, J., Hernandez, A., Kelly, G. A., Li, X., Onogi, K., Saarinen, S., Sokka, N., Allan, R. P., Andersson, E., Arpe, K., Balmaseda, M. A., Beljaars, A. C. M., Berg, L. V. D., Bidlot, J., Bormann, N., Caires, S., Chevallier, F., Dethof, A., Dragosavac, M., Fisher, M., Fuentes, M., Hagemann, S., Hólm, E., Hoskins, B. J., Isaksen, L., Janssen, P. A. E. M., Jenne, R., McNally, A. P., Mahfouf, J.F., Morcrette, J.-J., Rayner, N. A., Saunders, R. W., Simon, P., Sterl, A., Trenberth, K. E., Untch, A., Vasiljevic, D., Viterbo, P., and Woollen, J.: The ERA-40 re-analysis, Q. J. Roy. Meteor. Soc., 131, 2961-3012, doi:10.1256/qj.04.176, 2005.

van den Broeke, M., Smeets, P., Ettema, J., and Munneke, P. K.: Surface radiation balance in the ablation zone of the west Greenland ice sheet, J. Geophys. Res., 113, D13105, doi:10.1029/2007JD009283, 2008.

van den Broeke, M., Bus, C., Ettema, J., and Smeets, P.: Temperature thresholds for degree-day modelling of Greenland ice sheet melt rates, Geophys. Res. Lett., 37, L18501, doi:10.1029/2010GL044123, 2010.

van der Veen, C. J., Bromwich, D. H., Csatho, B. M., and Kim, C.: Trend surface analysis of Greenland accumulation, J. Geophys. Res., 106, 33909-33918, doi:10.1029/2001JD900156, 2001.

van de Wal, R. S. W.: Mass-balance modelling of the Greenland ice sheet: a comparison of an energy-balance model and a degreeday model, Ann. Glaciol., 23, 36-45, 1996.

Vizcaíno, M., Mikolajewicz, U., Gröger, M., Maier-Reimer, E., Schurgers, G., and Winguth, A. M. E.: Long-term ice sheetclimate interactions under anthropogenic greenhouse forcing simulated with a complex Earth System Model, Clim. Dynam., 31, 665-690, doi:10.1007/s00382-008-0369-7, 2008.

Vizcaíno, M., Mikolajewicz, U., Jungclaus, J., and Schurgers, G.: Climate modification by future ice sheet changes and consequences for ice sheet mass balance, Clim. Dynam., 34, 301-324, doi:10.1007/s00382-009-0591-y, 2010.

Von Storch, H., Langenberg, H., and Feser, F.: A spectral nudging technique for dynamical downscaling purposes, Month. Weather Rev., 128, 3664-3673, doi:10.1175/15200493(2000)128<3664:ASNTFD>2.0.CO;2, 2000.

Yoshimori, M. and Abe-Ouchi, A.: Sources of spread in multimodel projections of the Greenland ice-sheet surface mass balance, J. Climate, doi:10.1175/2011JCLI4011.1, 2012. 